\title{
A Novel Methodology for Estimating the Capacity and Level of Service for the New Mega Elliptical Roundabout Intersection
}

\author{
Ahmed I. Z. Mohamed (D), ${ }^{1,2}$ Yusheng Ci $\mathbb{D}^{1,3}$ and Yiqiu Tan ${ }^{1}$ \\ ${ }^{1}$ School of Transportation Science and Engineering, Harbin Institute of Technology, Harbin 150090, China \\ ${ }^{2}$ Department of Construction and Utilities Engineering, Faculty of Engineering, Zagazig University, Zagazig 44519, Egypt \\ ${ }^{3}$ Department of Civil \& Environmental Engineering, University of Washington, Box 352700, Seattle, WA 98195, USA
}

Correspondence should be addressed to Yusheng Ci; ciyusheng1999@126.com

Received 10 October 2019; Revised 19 December 2019; Accepted 21 January 2020; Published 12 March 2020

Guest Editor: Young-Ji Byon

Copyright (c) 2020 Ahmed I. Z. Mohamed et al. This is an open access article distributed under the Creative Commons Attribution License, which permits unrestricted use, distribution, and reproduction in any medium, provided the original work is properly cited.

\begin{abstract}
Mega elliptical roundabout is a new intersection on rural multilane highways. This intersection was developed in a previous paper using simulation data, and the authors found that it is better than interchange (full cloverleaf) in most scenarios of traffic flow. Basically, there are no guidelines or procedures for designing mega elliptical roundabout in AASHTO Green Book, Federal Highway Administration guides, and Highway Capacity Manual. Thus, the purpose of this study is to analyze the traffic operation performance and propose a methodology for calculating the capacity of mega elliptical roundabout and also the level of service by gap acceptance theory. Moreover, this research studied the influence of different values of truck ratios and also different values of a major highway speed on geometric design and traffic operation performance for mega elliptical roundabout. To validate the thoroughness of the proposed methodology, VISSIM simulations were conducted. This research will assist practitioners in determining the appropriate geometric design, assessing mega elliptical roundabout intersections, and making comparisons with other alternatives.
\end{abstract}

\section{Introduction}

The designs of conventional intersections cannot often relieve congestion without incurring increased conflicts and also significant improvement costs. Thus, there is a great need for alternative intersections offering the potential to reduce delay, improve safety, and reduce the influence on the environment with fewer effects and a lower cost than traditional solutions [1-4]. Therefore, the authors proposed a new type of intersections which is called "mega elliptical roundabout" in a previous paper [5]. Totally, they analyzed 1134 scenarios by VISSIM software to analyze the initial feasibility and determine the best scenarios of geometric design for mega elliptical roundabout intersections. They compared mega elliptical roundabout with the interchange (full cloverleaf). They found that mega elliptical roundabout as an intersection is better than the interchange (full cloverleaf) in some scenarios of traffic flow, but mega elliptical roundabout as an interchange is better than the interchange (full cloverleaf) in all scenarios of traffic flow relative to delay time, fuel consumption, and emission.

Based on the previous studies, intersection analysis models generally fall into three categories: simulation models, empirical models, and analytical models. Simulation models are useful in the initial feasibility analysis of new types of intersections which do not have Highway Capacity Manual (HCM) procedures and in comparing them with current intersections [6-14]. Empirical models rely on field data to develop relationships between geometric design features and performance measures such as capacity and delay [15-18]. Analytical models are based on the concept of gap acceptance theory, conflict theory, or probability theory [19-29].

The empirical models are generally better but cannot be used to analyze mega elliptical roundabout at present because mega elliptical roundabout is a new type of 
intersections, so no field data are available, while the initial feasibility analysis of mega elliptical roundabout has been introduced in another work by simulation models [5].

There are no guidelines or procedures for the design of mega elliptical roundabout in AASHTO Green Book, Federal Highway Administration (FHWA) guides, and Highway Capacity Manual (HCM). Therefore, this research analyzed the traffic operation performance and used the gap acceptance theory to propose a methodology for calculating the capacity of mega elliptical roundabout and also the level of service, to assist practitioners in determining the appropriate geometric design.

The remainder of this research is organized as follows. Section 2 introduces the literature review. Section 3 shows the basic concept of this study. Section 4 presents the proposed methodology. Section 5 shows the assumptions and built-up models. Section 6 presents the statistical analysis of built-up models. Section 7 demonstrates the case description and methodology validation. Section 8 introduces the sensitivity analysis. Section 9 gives the conclusions of this study and proposes future work.

\section{Review of the Previous Studies}

Mega elliptical roundabout is a new intersection. Its form is an elongated ellipse combining the best functions of the roundabout and the unconventional median U-turn (UMUT) intersection [5]. Therefore, the first efforts for this work looked at the studies related to estimating the capacity and level of service for roundabout, conventional median U-turn (MUT) intersection, and UMUT intersection to determine the ideal methodology to estimate the capacity and level of service for mega elliptical roundabout intersection.

2.1. Roundabout Intersection. Because vehicles enter the roundabout only when the gap in the circulating traffic is large enough, the capacity of the roundabout depends primarily on the circulating flow and the availability of gaps. Therefore, roundabout capacity is measured in terms of the entry capacity, whether by gap acceptance theory [30-32], empirical models [33-39], simulation models [40-43], conflict theory [44], or others [45-47].

Yap et al. [48] examined the worldwide state-of-the-art in roundabout capacity modeling, covering the three main methodologies on which models are based: fully empirical, gap acceptance, and simulation. They found that due to their limitations, each of these methodologies on its own cannot completely explain the complex behavioural and physical processes involved in roundabout entries; hence, all the models require strong semiempirical or fully empirical bases using data obtained from their countries of origin. Differences in driver behaviour and methodologies thus result in differences in predicted capacities by the various models, and although local calibration allows some transferability, it is often limited by the availability of data or an incomplete understanding of the relationships between model parameters and capacity.
Little research exists from the viewpoint of the weaving section in capacity estimation for the roundabout. Diah et al. [49] introduced a model to predict the weaving section flow at the weaving area of Malaysian conventional roundabout by regression models, while Diah et al. [50] studied the relation between the roundabout performance, geometric design of roundabout, and weaving section flow process using Paramics software. Wang and Yang [51] proposed a method to estimate the capacity of the roundabout by modeling weaving gap acceptance at the weaving sections, but they did not calibrate their method.

In the literature, only one paper by $\mathrm{Wu}$ and Brilon [52] treated the whole roundabout intersection as one entity. They believe that the total roundabout capacity can be obtained according to traffic volumes for the movements at the intersection by their method, but they did not calibrate their method by empirical data.

The Highway Capacity Manual [53] only provides a methodology for estimating the capacity of each entry lane and the level of service for the single-lane and multilane roundabout. However, HCM [53] neglected the weaving section when designing the roundabout.

2.2. MUT Intersection. Al-masaeid [54] used empirical and gap acceptance approaches to predict the capacity and the delay of U-turn movement at median openings of four lanedivided arterials. Florida Department of Transportation (FDOT) sponsored a lot of projects to develop a model to estimate delay and travel time for two alternatives: right turn followed by U-turn (RTUT) and direct left turn (DLT) [55-57]. Zhou et al. [58] assessed the operational effects of an RTUT and a DLT. They used field data from eight sites in the Tampa and Clearwater areas of Florida to develop delay and travel-time models. They found that vehicles making a DLT experienced longer delay and travel times than those that made an RTUT.

Zhou et al. [59] introduced the regression model for predicting the average weaving speed in weaving segments at RTUT. Also, they developed a theoretical equation to determine the optimal location of median openings on roadways. Liu et al. [60] analyzed the operational effects of RTUT as an alternative to DLT. They collected the field data from 34 sites in central Florida. They developed a binary logit model to the number of drivers who would like to make an RTUT instead of a DLT under different roadway geometric and traffic conditions.

Zhao et al. [61] proposed a lane-based optimization model for the integrated design of the MUT and formulated a multiobjective mixed-integer nonlinear programming problem to optimize the intersection design types, the layout of the intersection, and the signal timings simultaneously. They conducted a numerical analysis to evaluate the performance of the proposed design under various demand and layout scenarios, but they did not calibrate their method by empirical data. Dash et al. [62] used four different methods to estimate the critical gap of U-turns: modified Raff, maximum likelihood, macroscopic probability equilibrium, 
and merging behaviour approach by collecting data at seven median openings in India.

The Highway Capacity Manual [53] provides a methodology for estimating the capacity and level of service for MUT intersection. However, HCM [53] neglected the weaving section when designing the MUT intersection.

2.3. UMUT Intersection. Shahi and Choupani [15] conducted traffic operation analysis of the UMUT design by the field data. They developed a regression model to calculate the travel time of the minor street through traffic, travel time of the left-turn traffic, speed of the nonweaving flows, weaving time, and speed of the U-turning vehicles. The developed models have been compared with the RTUT models which have been developed by FDOT [55-57]. They found that FDOT models always overestimate travel times.

\section{Basic Concept}

3.1. Mega Elliptical Roundabout Characteristics. As shown in Figure 1, the mega elliptical roundabout has two essential features.

The first feature is the central island that is elongated on the major highway for providing enough length for weaving sections. Moreover, the form of this island is an ellipse that has an ellipse element $(b)$ for providing a suitable basic ellipse roadway radius in order to be appropriate for heavy vehicles that make a U-turn on basic ellipse roadway.

The second feature is the ellipse roadway, which has three parts: the basic ellipse roadway, weaving sections, and nonweaving sections [5].

\subsection{The Operation Analysis of Mega Elliptical Roundabout.} The mega elliptical roundabout reroutes both of the through and left-turning traffic coming from a minor highway through right turns in order to merge them with the traffic of a major highway on the weaving sections, followed by U-turn on a basic ellipse roadway. Left-turning traffic for a major highway must also make a U-turn on a basic ellipse roadway then a right turn on a minor highway. The conflict between merging the through traffic for a major highway and the traffic from cross-highway can be treated by putting a "Yield" sign on a minor highway and basic ellipse roadway. It gives the priority for a major highway through traffic, as shown in Figure 1.

\subsection{The Weaving Pattern on Mega Elliptical Roundabout.}

To analyze mega elliptical roundabout intersection, it first needs to be broken down into four parts as shown in Figure 2. Second, it needs to convert the intersection turning movements into the weaving volumes. As shown in Figure 2 the volumes are $V_{1}$ to $V_{12}$.

Two weaving patterns are defined in the HCM [53]. According to HCM [53], in two-sided weaving sections, only the movement from ramp to ramp is considered a weaving movement, where the movement of the major highway does not need any lane change, while the minor highway movement needs more than one lane change.

The vehicle movement weaving pattern on mega elliptical roundabout is like a two-sided weaving section configuration where the right hand on-ramp is followed by the left hand off-ramp or vice versa. As shown in Figure 3, basic ellipse roadway-to-minor-highway vehicles must cross all the lanes in order to execute their desired maneuver, while the major highway vehicles do not need any lane change. Note that the movement in part 1 is like that in part 3. Also, as shown in Figure 4, the minor highway to basic ellipse roadway vehicles must cross all the lanes in order to execute their desired maneuver, while the nonweaving vehicles do not need any lane change. Note that the movement in part 2 is like that in part 4 .

There are few studies concerning the operation of twosided weaving sections. Lertworawanich and Elefteriadou [63-65] proposed a methodology for calculating the capacity for all weaving section types based on linear programing techniques and gap acceptance theory. They compared this methodology with the HCM [66] weaving sections model and field capacity. They found that this methodology provides capacity estimates nearer to the observed capacity values in the field than HCM $[66,67]$.

Also, in two papers by Zhang and Rakha $[68,69]$ and a doctoral thesis by Yihua Zhang, analytical models for calculating the capacity of all weaving section types were developed using simulated data collected by INTEGRATION software. They validated the analytical models against field observations gathered in Toronto. They found a high consistency between analytical models and field. Also, they found that the proposed analytical models calculate the capacity for weaving sections within $12 \%$ of the simulated data, while HCM [66] procedures exhibit errors within 114\%.

However, in this research, we have decided to use the gap acceptance model proposed by HCM [53] with some modifications to suit estimation of the weaving section capacity for mega elliptical roundabout for the following reasons:

(1) As described in Section 2, most researchers estimated roundabout capacity in terms of entry capacity. However, the mega elliptical roundabout differs from a roundabout in traffic operations [5].

(2) Researchers who analyzed the roundabout from the viewpoint of the weaving section did not calibrate their method. Also, the weaving pattern on mega elliptical roundabout is like a two-sided weaving section, while the weaving pattern on the roundabout is like a one-side weaving section.

(3) Researchers who analyzed the MUT and UMUT intersections from the viewpoint of the weaving section did not estimate the weaving section capacity.

(4) HCM [53] neglected the weaving section when designing the roundabout and MUT intersection.

(5) Mega elliptical roundabout is new idea for intersections, so no field data are available at present. 


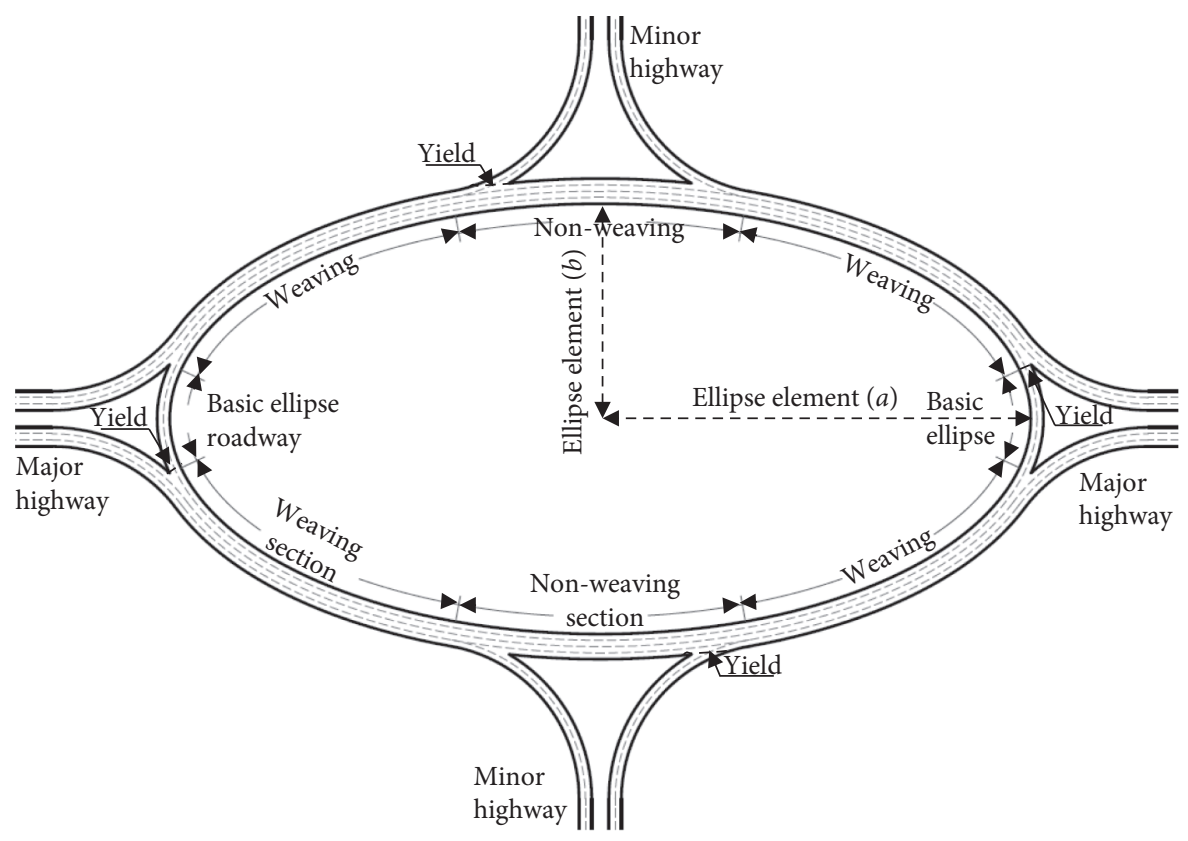

FIgUre 1: Geometric elements for mega elliptical roundabout.

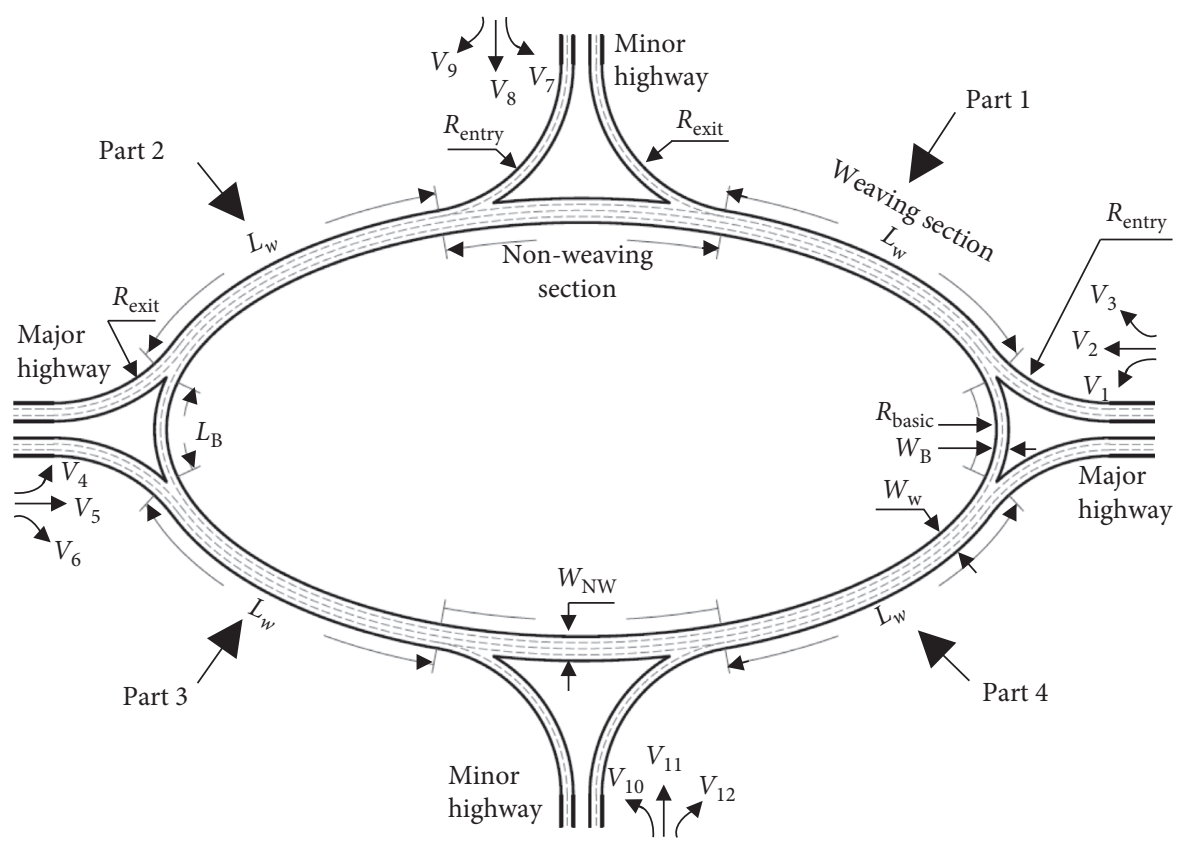

Figure 2: Flow stream definitions.

(6) HCM is an international reference manual supervised by an independent committee of experts in this field and therefore is often the basis for policy decisions when choosing an intersection.

\section{Methodology}

This section aims to propose a methodology for calculating the capacity of mega elliptical roundabout in addition to the level of service by gap acceptance theory. The general methodology for analyzing mega elliptical roundabout intersection operations is shown in the flowchart in Figure 5. These methodology steps are described in detail as follows:

Step 1: adjust volume.

HCM [53] proposed equation (1) to convert demand volumes to flow rates at equivalent ideal conditions.

$$
v_{i}=\frac{V_{i}}{\left(\mathrm{PHF} * f_{\mathrm{HV}}\right)},
$$




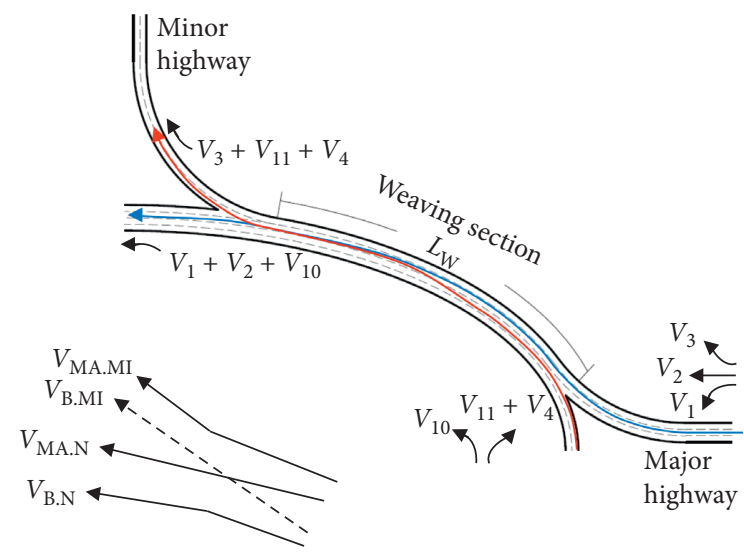

FIGURE 3: The weaving pattern for weaving section on mega elliptical roundabout (part 1). $V_{\text {MA.MI }}=$ traffic volume in outer lane from major highway to minor highway $(\mathrm{veh} / \mathrm{h})-V_{3} ; V_{\text {MA.N }}=$ traffic volume from major highway to nonweaving section (veh/h)$V_{2}+V_{1} ; V_{\text {B.MI }}=$ conflicting volume from basic ellipse roadway to minor highway (veh/h) $-V_{11}+V_{4} ; V_{\text {B.N }}=$ traffic volume in inner lane from basic ellipse roadway to nonweaving section (veh/h)- $V_{10}$; $V_{\mathrm{W}}=$ total weaving volume in the weaving section $(\mathrm{veh} / \mathrm{h})-V_{\mathrm{B} . \mathrm{MI}}$; $V_{\mathrm{NW}}=$ total nonweaving volume in the weaving section $(\mathrm{veh} / \mathrm{h})-$ $V_{\text {MA.MI }}+V_{\text {MA.N }}+V_{\text {B.N. }}$.

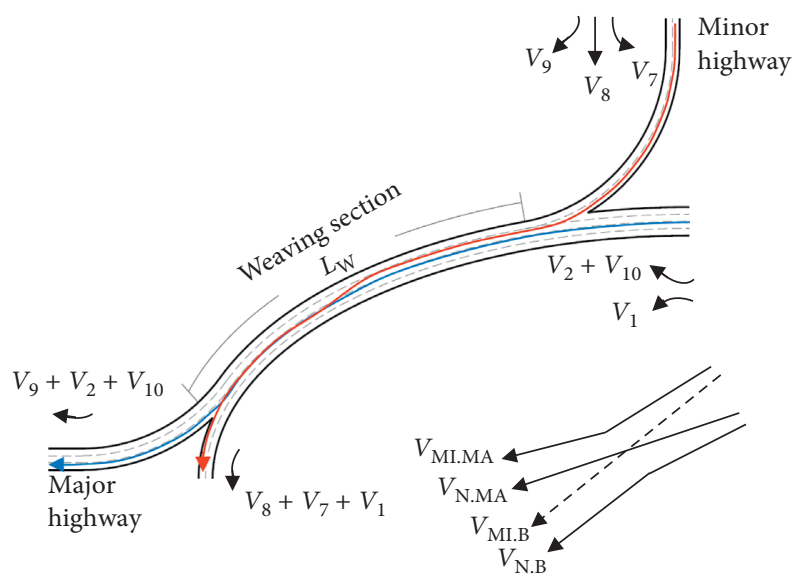

FIGURE 4: The weaving pattern for weaving section on mega elliptical roundabout (part 2). $V_{\text {MI.MA }}=$ traffic volume in outer lane from minor highway to major highway (veh/h) $-V_{9}$; $V_{\text {MI.B }}=$ conflicting traffic volume from minor highway to basic ellipse roadway (veh/h) $-V_{8}+V_{7} ; V_{\text {N.MA }}=$ traffic volume from nonweaving section to major highway (veh/h) $-V_{2}+V_{10}$; $V_{\mathrm{N} . \mathrm{B}}=$ traffic volume in inner lane from nonweaving section to basic ellipse roadway $(\mathrm{veh} / \mathrm{h})-V_{1} ; V_{\mathrm{W}}=$ total weaving volume in the weaving section $(\mathrm{veh} / \mathrm{h})-V_{\mathrm{MI} . \mathrm{B}} ; V_{\mathrm{NW}}=$ total nonweaving volume in the weaving section $(\mathrm{veh} / \mathrm{h})-V_{\text {MI.MA }}+V_{\text {N.MA }}+V_{\text {N.B. }}$.

where $v$ is the peak 15-minute flow rate in an hour (pcl h), $V$ is the hourly volume (veh/h), PHF is the peak-hour factor, and $f_{\mathrm{HV}}$ is the heavy vehicle adjustment factor estimated in

$$
f_{\mathrm{HV}}=\frac{1}{1+P_{T}\left(E_{T}-1\right)},
$$

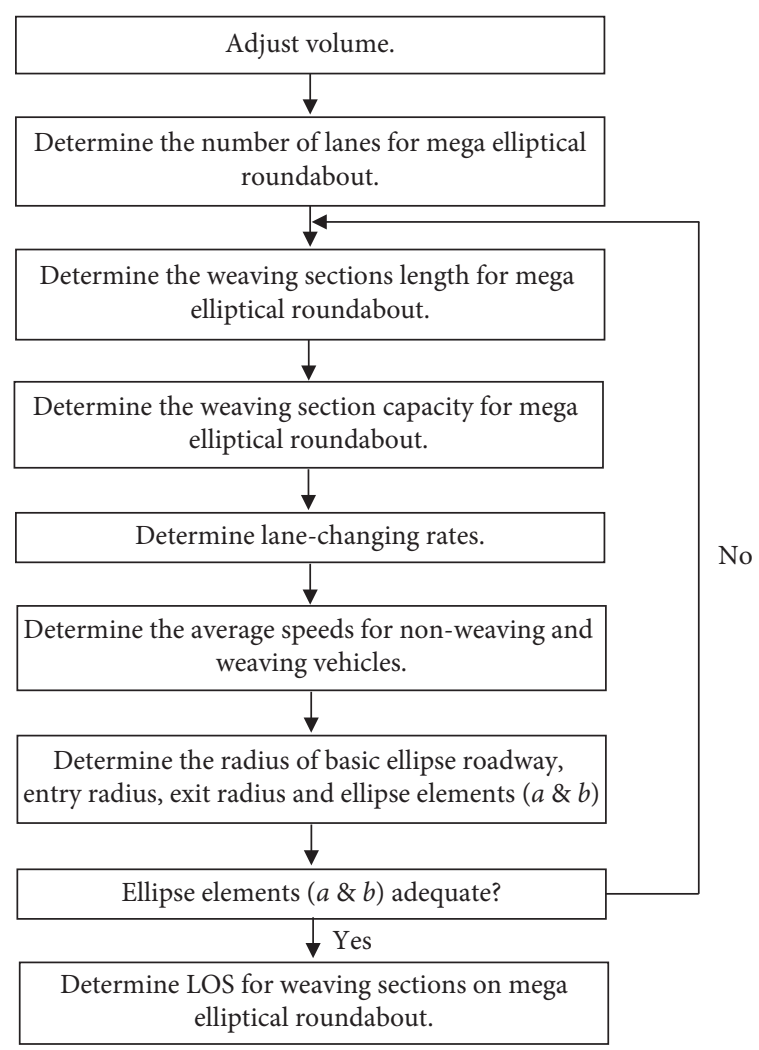

Figure 5: Methodology flowchart.

where $P_{T}$ is the proportion of buses and trucks in a traffic stream and $E_{T}$ is passenger car equivalents for buses and trucks. By following HCM [53], the $E_{T}$ value is assumed as 1.5 , which is the proposed value for intersections in the level area.

Step 2: determine the number of lanes for mega elliptical roundabout.

Mohamed et al. [5] found that the best scenarios of mega elliptical roundabout are the following: when the number of lanes of weaving section $\left(W_{\mathrm{W}}\right)$ equals the number of lanes of the nonweaving section $\left(W_{\mathrm{NW}}\right)$ and also equals the number of lanes of major highway plus one lane.

$W_{\mathrm{W}}=W_{\mathrm{NW}}=$ number of lanes of major highway +1

Moreover, the number of lanes of basic ellipse roadway $\left(W_{\mathrm{B}}\right)$ equals the number of lanes of minor highway.

$W_{\mathrm{B}}=$ number of lanes of minor highway

where $W_{\mathrm{W}}$ is the number of lanes of weaving section, $W_{\mathrm{NW}}$ is the number of lanes of the nonweaving section, and $W_{B}$ is the number of lanes of basic ellipse roadway, as shown in Figure 2.

Step 3: determine the weaving sections length for mega elliptical roundabout.

HCM [53] defined the weaving section length (short length) as the distance between the end points of any barrier markings that prohibit or discourage lane 
changing. Consequently, several geometric design scenarios for mega elliptical roundabout intersection were drawn using AutoCAD software to determine the relationship between the weaving section length $\left(L_{\mathrm{W}}\right)$ and ellipse elements $(a)$ and $(b)$, as described in Section 5. The following is a regression equation that can estimate the length of weaving section based upon ellipse elements $(a)$ and $(b)$.

If $b=0.5 a$

$$
L_{\mathrm{W}}=0.868 a-7.271
$$

If $b=0.75 a$

$$
L_{\mathrm{W}}=0.721 a+12.528,
$$

where $a$ is ellipse element $(\mathrm{ft}), b$ is ellipse element $(\mathrm{ft})$, and $L_{\mathrm{W}}$ is the weaving section length for mega elliptical roundabout intersection (ft), as shown in Figure 2.

Step 4: determine weaving section capacity.

The HCM [53] proposed equation (5) to estimate the capacity. It is important to mention that the $N_{\mathrm{WL}}$ term in the equation of HCM [53] has been deleted because it equals zero for two-sided weaving sections.

$$
\begin{aligned}
C= & {\left[C_{\mathrm{H}}-\left[438.2(1+\mathrm{VR})^{1.6}\right]+\left(0.0765 * L_{\mathrm{W}}\right)\right] } \\
& * W_{\mathrm{W}} * f_{\mathrm{HV}},
\end{aligned}
$$

where $C$ is the capacity for weaving section (veh/h/ln), $C_{\mathrm{H}}$ is the capacity for major highway under ideal conditions and free-flow speed ( $\mathrm{pc} / \mathrm{h} / \mathrm{ln})$, and VR is the weaving ratio. It is the ratio of the weaving flow rate to the total flow rate in weaving section $(\mathrm{pc} / \mathrm{h})$ estimated in

$$
\mathrm{VR}=\frac{v_{\mathrm{W}}}{\left(v_{\mathrm{W}}+v_{\mathrm{NW}}\right)}
$$

where $v_{\mathrm{W}}$ is the total weaving flow rate $(\mathrm{pc} / \mathrm{h})$ and $v_{\mathrm{NW}}$ is the total nonweaving flow rate in weaving section (pc/h).

Step 5: determine lane-changing rates.

Lane changes fall into three different categories: (1) Lane-changes which must be made by the weaving vehicles to complete a weaving maneuver successfully happen when the weaving vehicles leave weaving section on the lane nearest to their entry point and enter weaving section on the lane nearest to their desired destination. (2) Additional lane changes which may be made by the weaving vehicles happen when weaving vehicles enter weaving section on the lane next to the lane nearest to their desired destination or these vehicles leave on the lane next to the lane nearest to their entry point. These lane changes are based upon driver choices because these are optional. (3) Lane changes which may be made by nonweaving vehicles in weaving section are generally made for avoiding weaving turbulence. These lane changes are based upon driver choices because these are always optional [67].

As shown in Figure 3, the basic ellipse roadway to minor highway vehicles must make one required lane change, assuming they enter the weaving section on the right lane of basic ellipse roadway. Thus, $\mathrm{LC}_{\mathrm{BM}}=1$. As shown in Figure 4, the minor highway to basic ellipse roadway vehicles must also make one required lane change, assuming they enter the weaving section on the left lane of minor highway. Thus, $\mathrm{LC}_{\mathrm{MB}}=1$. The following lane-changing values can be computed from equations (7) and (8)

For part 1 or part 3

$$
\mathrm{LC}_{\mathrm{MIN}}=\mathrm{LC}_{\mathrm{BM}} * v_{\mathrm{B} . \mathrm{MI}} \text {. }
$$

For part 2 or part 4

$$
\mathrm{LC}_{\mathrm{MIN}}=\mathrm{LC}_{\mathrm{MB}} * v_{\mathrm{MI} . \mathrm{B}} \text {, }
$$

where $\mathrm{LC}_{\mathrm{MIN}}$ is the minimum number of the lane changes $(\mathrm{lc} / \mathrm{h}), \mathrm{LC}_{\mathrm{BM}}$ is the minimum number of the required lane changes for basic ellipse roadway to minor highway $(\mathrm{lc} / \mathrm{h}), v_{\mathrm{B} . \mathrm{MI}}$ is the flow rate of basic ellipse roadway to minor highway ( $\mathrm{pc} / \mathrm{hr}$ ), $\mathrm{LC}_{\mathrm{MB}}$ is the minimum number of the required lane changes for minor highway to basic ellipse roadway, and $v_{\mathrm{MI}}$ is the flow rate of minor highway to basic ellipse roadway (pc/ hr).

The total number of the lane changes made within the weaving section can be predicted by expanding the value of $\mathrm{LC}_{\mathrm{MIN}}$ to include the number of optional lane changes which are made by both the weaving vehicles and the nonweaving vehicles. The total number of the lane changes which are made by weaving vehicles is calculated as

$\mathrm{LC}_{\mathrm{W}}=\mathrm{LC}_{\mathrm{MIN}}+0.39\left[\left(L_{\mathrm{W}}-300\right)^{0.5} \mathrm{~W}_{\mathrm{W}}^{2}(1+\mathrm{ID})^{0.8}\right]$,

where $\mathrm{LC}_{\mathrm{W}}$ is the total number of lane changes made by weaving vehicles $(\mathrm{pc} / \mathrm{h})$ and ID is interchange density (int $/ \mathrm{mi}$ ).

The total number of the lane changes which are made by the nonweaving vehicles is calculated as follows.

Firstly, estimate the index

$$
\operatorname{INDEX}=\frac{\left(L_{\mathrm{W}} * \mathrm{ID} * v_{\mathrm{NW}}\right)}{10000}
$$

Then, select the equation from Table 1 based upon the index value. 
TABLE 1: The equations for estimating the number of nonweaving lane changes [53].

\begin{tabular}{lc}
\hline Index & Equation for LC $\mathrm{NW}_{\mathrm{NW}}$ \\
\hline$\leq 1300$ & $\mathrm{LC}_{\mathrm{NW} 1}=\left(0.206 v_{\mathrm{NW}}\right)+\left(0.542 L_{\mathrm{W}}\right)-\left(192.6 W_{\mathrm{W}}\right)$ \\
$>1300$ and $<1950$ & $\mathrm{LC}_{\mathrm{NW}}=W_{\mathrm{W}}+\left[\left(\mathrm{LC}_{\mathrm{NW} 2}-\mathrm{LC}_{\mathrm{NW} 1}\right) *[\mathrm{INDEX}-1300 / 650]\right]$ \\
$\geq 1950$ & $\mathrm{LC}_{\mathrm{NW} 2}=2135+0.233\left(v_{\mathrm{NW}}-2000\right)$ \\
\hline
\end{tabular}

Here, $\mathrm{LC}_{\mathrm{NW}}$ is the total number of the lane changes which are made by the nonweaving vehicles $(\mathrm{pc} / \mathrm{h})$. The value of $\mathrm{LC}_{\mathrm{NW}}$ must be equal to or greater than zero. The total number of lane changes occurring in weaving section $\left(\mathrm{LC}_{\mathrm{All}}\right)$ is estimated as

$$
\mathrm{LC}_{\mathrm{ALL}}=\mathrm{LC}_{\mathrm{W}}+\mathrm{LC}_{\mathrm{NW}}
$$

Step 6: determine the average speeds for nonweaving and weaving vehicles.

The average speeds for nonweaving and weaving vehicles are estimated by the following regression-based equations proposed by HCM [53]:

$$
\begin{aligned}
S_{\mathrm{W}} & =15+\left[\frac{(\mathrm{FFS}-15)}{(1+\mathrm{WI})}\right], \\
S_{\mathrm{NW}} & =\mathrm{FFS}-\left(0.0072 * \mathrm{LC}_{\mathrm{MIN}}\right)-\left(\frac{(0.0048 * v)}{W_{\mathrm{W}}}\right), \\
\mathrm{WI} & =0.226\left(\frac{\mathrm{LC}_{\mathrm{ALL}}}{L_{\mathrm{W}}}\right)^{0.789}, \\
S & =\left(\frac{v_{\mathrm{W}}+v_{\mathrm{NW}}}{\left(v_{\mathrm{W}} / s_{\mathrm{W}}\right)+\left(v_{\mathrm{NW}} / s_{\mathrm{NW}}\right)}\right),
\end{aligned}
$$

where $S_{\mathrm{W}}$ is the average speed of the weaving vehicles $(\mathrm{mi} / \mathrm{h})$, FFS is the free-flow speed of the major highway $(\mathrm{mi} / \mathrm{h})$, WI is the weaving intensity factor of the weaving speed, $S_{\mathrm{NW}}$ is the average speed of the nonweaving vehicles $(\mathrm{mi} / \mathrm{h}), v$ is the total nonweaving and weaving flow rate $(\mathrm{pc} / \mathrm{h})$, and $S$ is the average speed of all the vehicles in weaving sections $(\mathrm{mi} / \mathrm{h})$.

Step 7: determine the radius of basic ellipse roadway, entry radius, exit radius, and ellipse elements ( $a$ and $b$ ).

AASHTO [70] proposed equation (13) to estimate the radius of basic ellipse roadway, entry radius, and exit radius.

$$
R=\frac{S^{\wedge} 2}{15(f+0.01 e)}
$$

where $R$ is radius of basic ellipse roadway which is equal to the entry radius as well the exit radius ( $\mathrm{ft}$ ), as shown in Figure 2. $f$ is side friction factor, and $e$ is rate of basic ellipse roadway superelevation.
As described in Section 5, the ellipse elements $(a)$ and (b) can be estimated based upon the radius of basic ellipse roadway $(R)$ by the following regression equations.

If $b=0.5 a$

$$
a=3.954 R-27.427 .
$$

If $b=0.75 a$

$$
a=1.778 R-8.846 .
$$

Step 8: determine LOS for weaving sections on mega elliptical roundabout.

The HCM [53] proposed equation (16) to estimate the density from the average speed.

$$
D=\left(\frac{\left(v / W_{\mathrm{W}}\right)}{S}\right)
$$

where $D$ is average density within the weaving section (pc/ $\mathrm{mi} / \mathrm{ln}$ ) and $v$ is the total nonweaving and weaving flow rate ( $\mathrm{pc} / \mathrm{h})$. From Table 2, we can determine the LOS.

\section{Built-Up Models}

By using AutoCAD software, several geometric design scenarios for mega elliptical roundabout intersection were drawn. The linear regression analysis was also used to determine the following relationships:

The relationship between the weaving section length $\left(L_{\mathrm{W}}\right)$ and the ellipse elements $(a)$ and $(b)$-equations (3) and (4)

The relationship between the radius of basic ellipse roadway ( $\left.R_{\text {basic }}\right)$ and the ellipse elements $(a)$ and $(b)$ equations (14) and (15)

The relationship between the length of basic ellipse roadway $\left(L_{\mathrm{B}}\right)$ and the ellipse elements $(a)$ and $(b)$ equations (17) and (18)

The mega elliptical roundabout provides appropriate storage lanes for vehicles making a U-turns by providing a sufficient length of basic ellipse roadway. The length of basic ellipse roadway $\left(L_{\mathrm{B}}\right)$ can be estimated based upon the ellipse elements $(a)$ and $(b)$ by the following regression equations:

$$
\text { If } b=0.5 a \text {, }
$$

$$
L_{\mathrm{B}}=0.235 a-29.365 \text {. }
$$

If $b=0.75 a$, 
TABLE 2: Level of service for weaving sections on mega elliptical roundabout intersection [53].

\begin{tabular}{lc}
\hline Level of service & Density \\
\hline A & $0-12$ \\
B & $>12-24$ \\
C & $>24-32$ \\
D & $>32-36$ \\
E & $>36-40$ \\
F & $>40$ \\
\hline
\end{tabular}

$$
L_{B}=0.524 a-44.016,
$$

where $L_{\mathrm{B}}$ is the length of basic ellipse roadway $(\mathrm{ft})$, as shown in Figure 2.

The regression models were developed using AutoCAD data with the following assumptions and characteristics:

The entry radius of major highway $\left(R_{\text {entry }}\right)$ equals the entry radius of minor highway, as shown in Figure 2

The entry radius $\left(R_{\text {entry }}\right)$ equals the radius of basic ellipse roadway $\left(R_{\text {basic }}\right)$ and also equals the radius of exit $\left(R_{\text {exit }}\right)$ whether for the minor or major highway, as shown in Figure 2

Lane width equals $12.00 \mathrm{ft}$

Median width of the major and minor highway equals $32.80 \mathrm{ft}$

The minimum value for an ellipse element $(a)$ in all scenarios equals $328 \mathrm{ft}$

The maximum value for an ellipse element $(a)$ in scenarios when $(b=0.5 a)$ equals $4920 \mathrm{ft}$

The maximum value for an ellipse element $(a)$ in scenarios when $(b=0.75 a)$ equals $2130 \mathrm{ft}$

The intersection is four-legged

The intersection is a six-lane-divided highway with a four-lane-divided highway

\section{Statistical Analysis of Built-Up Models}

The regression models were developed using the data that were compiled by the AutoCAD software, and a linear regression method was accomplished using SPSS software. Regression results of the relationship between the weaving section length $\left(L_{\mathrm{W}}\right)$ and ellipse element $(a)$ and also of the relationship between the length of basic ellipse roadway $\left(L_{\mathrm{B}}\right)$ and ellipse element $(a)$ when $(b=0.5 a)$ and also when $(b=0.75 a)$ are shown in Table 3. Moreover, regression results of the relationship between the ellipse element $(a)$ and the radius of basic ellipse roadway $(R)$ when $(b=0.5 a)$ and also when $(b=0.75 a)$ are shown in Table 4 .

$R$-square value of all linear models is very high (99.9\%), which means that $99.9 \%$ of the variation independent variables can be explained by these models. Also, for all models, the value of the standard error of the estimate (positive square root of variance of the errors), which typically measures the difference between dependent variables value with the "true" value, is relatively small.
Similar to the standard error of the estimate, the standard error presents the standard error of the coefficient estimates. Essentially, they measure how these coefficients vary from sample to sample. The models are more reliable as the standard error decreases. The $t$-statistic is the coefficient divided by its standard error. This is based on the following assumption: if the standard errors of the estimate (population errors) are normally distributed, then it can be shown that the sample estimates for coefficients of the model follow a $t$-distribution [71]. The $t$-statistic represents the size of the standard error relative to the estimated coefficient; therefore, the model quality improves as the absolute value of $t$-statistic increases. For those reasons, we can conclude that these models are adequate for predicting the dependent variables.

\section{Model Validation and Analysis}

7.1. Case Description. To validate the thoroughness of the proposed methodology, VISSIM simulations were conducted. Mega elliptical roundabout intersection which was analyzed was the intersection of the six-lane-divided highway with the four-lane-divided highway, where the intersection was four-legged. The study used hypothetical values of traffic volumes. Traffic volumes of the major highway approaches were varied from 1000 to $2500 \mathrm{veh} / \mathrm{h} /$ approach with $500 \mathrm{veh} / \mathrm{h} /$ approach increments (i.e., 4 volume levels). Also, traffic volumes of the minor highway were varied from 500 to $1000 \mathrm{veh} / \mathrm{h} / \mathrm{approach}$ with $500 \mathrm{veh} / \mathrm{h} /$ approach increments (i.e., 2 volume levels). The left-turn volume percentage, the right-turn volume percentage, and the proportion of trucks and buses were considered equal to $20 \%$. The major highway speed was considered $62 \mathrm{mi} / \mathrm{h}$, the peak-hour factor (PHF) equals 0.95 , the basic ellipse roadway superelevation equals $2 \%$, and the ellipse element $(b)$ equals 0.75 ellipse element $(a)$. In total, seven scenarios of traffic volume combination for the mega elliptical roundabout design were analyzed, including different levels of the major highway volume and minor highway volume.

7.2. Methodology Validation. To test the accuracy of the proposed methodology, the simulation models for each scenario listed above were built with the VISSIM software package. The parameters were obtained based on the observation of the real two-sided weaving sections in Harbin to ensure its rationality, and the parameters of the VISSIM simulation model must be modified accordingly. Seven simulations of different random seeds were conducted, and the final results were the average values over seven simulations. The results of the estimation models and simulations for density and average speed are given in Table 5 when the traffic volume for the minor highway equals $500 \mathrm{veh} / \mathrm{h}$. Moreover, these results are given in Table 6 when the traffic volume for the minor highway equals $1000 \mathrm{veh} / \mathrm{h}$.

For all traffic volume cases on the major highway and minor highway, there was no significant difference in methodology results and simulation for estimating average 
TABLE 3: Regression results of the relationship between $L_{\mathrm{W}}, L_{\mathrm{B}}, a$, and $b$.

\begin{tabular}{|c|c|c|c|c|c|c|}
\hline \multirow{2}{*}{ Equation number } & \multirow{2}{*}{ Dependent variables } & & \multicolumn{2}{|c|}{ Independent variables } & \multirow{2}{*}{ Std. error of the estimate } & \multirow{2}{*}{$R^{2}$} \\
\hline & & & Constant & $a(\mathrm{ft})$ & & \\
\hline \multicolumn{7}{|l|}{ If $b=0.5 a$} \\
\hline & & Coefficients & -7.271 & 0.868 & & \\
\hline 3 & $L_{\mathrm{W}}$ & $\begin{array}{c}\text { Standard error } \\
t \text {-statistics }\end{array}$ & $\begin{array}{c}2.658 \\
-2.735\end{array}$ & $\begin{array}{c}0.001 \\
849.058\end{array}$ & 5.027 & 1.00 \\
\hline 20 & $L_{\mathrm{B}}$ & $\begin{array}{c}\text { Coefficients } \\
\text { Standard error } \\
t \text {-statistics }\end{array}$ & $\begin{array}{c}-29.365 \\
5.219 \\
-5.627 \\
\end{array}$ & $\begin{array}{c}0.235 \\
0.002 \\
117.287 \\
\end{array}$ & 9.869 & 0.999 \\
\hline \multicolumn{7}{|l|}{ If $b=0.75 a$} \\
\hline 政 & $L_{\mathrm{W}}$ & $\begin{array}{c}\text { Coefficients } \\
\text { Standard error } \\
t \text {-statistics }\end{array}$ & $\begin{array}{c}12.528 \\
2.357 \\
5.315\end{array}$ & $\begin{array}{c}0.721 \\
0.002 \\
382.886\end{array}$ & 3.321 & 1.00 \\
\hline 21 & $L_{\mathrm{B}}$ & $\begin{array}{c}\text { Coefficients } \\
\text { Standard error } \\
t \text {-statistics }\end{array}$ & $\begin{array}{c}-44.016 \\
4.736 \\
-9.294\end{array}$ & $\begin{array}{c}0.524 \\
0.004 \\
138.455\end{array}$ & 6.673 & 1.00 \\
\hline
\end{tabular}

TABLE 4: Regression results of the relationship between $a, R$, and $b$.

\begin{tabular}{|c|c|c|c|c|c|c|}
\hline \multirow{2}{*}{ Equation number } & \multirow{2}{*}{ Dependent variables } & & \multicolumn{2}{|c|}{ Independent variables } & \multirow{2}{*}{ Std. error of the Estimate } & \multirow{2}{*}{$R^{2}$} \\
\hline & & & Constant & $R(\mathrm{ft})$ & & \\
\hline \multicolumn{7}{|l|}{ If $b=0.5 a$} \\
\hline & & Coefficients & -27.427 & 3.954 & & \\
\hline 17 & $a$ & $\begin{array}{l}\text { Standard error } \\
t \text {-statistics }\end{array}$ & $\begin{array}{c}3.715 \\
-7.383\end{array}$ & $\begin{array}{c}0.006 \\
705.367\end{array}$ & 6.968 & 1.00 \\
\hline \multicolumn{7}{|l|}{ If $b=0.75 a$} \\
\hline 18 & $a$ & $\begin{array}{c}\text { Coefficients } \\
\text { Standard error } \\
t \text {-statistics }\end{array}$ & $\begin{array}{c}-8.846 \\
1.128 \\
-7.84\end{array}$ & $\begin{array}{c}1.778 \\
0.002 \\
1115.688\end{array}$ & 1.580 & 1.00 \\
\hline
\end{tabular}

TABle 5: Results of methodology, simulations, and relative error when the traffic volume for the minor highway equals 500 veh/h.

\begin{tabular}{|c|c|c|c|c|c|c|c|}
\hline \multirow{2}{*}{$\begin{array}{l}\text { Traffic volume for } \\
\text { the major highway }\end{array}$} & & \multicolumn{3}{|c|}{ Part 1 or part 3} & \multicolumn{3}{|c|}{ Part 2 or part 4} \\
\hline & & Average speed $(\mathrm{mi} / \mathrm{h})$ & Density (pc/mi/ln) & LOS & Average speed (mi/h) & Density (pc/mi/ln) & LOS \\
\hline \multirow{3}{*}{1000} & VISSIM & 52.85 & 7.6 & $\mathrm{~A}$ & 52.7 & 6.7 & $\mathrm{~A}$ \\
\hline & Methodology & 55.2 & 8.4 & $\mathrm{~A}$ & 56.2 & 7.2 & $\mathrm{~A}$ \\
\hline & Relative error & $4.4 \%$ & $10.5 \%$ & & $6.6 \%$ & $7.4 \%$ & \\
\hline \multirow{3}{*}{1500} & VISSIM & 51.9 & 10.7 & $\mathrm{~A}$ & 51.88 & 8.7 & $\mathrm{~A}$ \\
\hline & Methodology & 53.9 & 11.8 & $\mathrm{~A}$ & 55.8 & 9.3 & $\mathrm{~A}$ \\
\hline & Relative error & $3.8 \%$ & $10.28 \%$ & & $7.5 \%$ & $6.9 \%$ & \\
\hline \multirow{3}{*}{2000} & VISSIM & 49.5 & 14.2 & $\mathrm{~B}$ & 50.2 & 11.03 & $\mathrm{~A}$ \\
\hline & Methodology & 52.4 & 15.5 & $\mathrm{~B}$ & 55.4 & 11.5 & A \\
\hline & Relative error & $5.8 \%$ & $9.1 \%$ & & $10.3 \%$ & $4.2 \%$ & \\
\hline \multirow{3}{*}{2500} & VISSIM & 43.7 & 19.6 & $\mathrm{~B}$ & 45.9 & 14.2 & $\mathrm{~B}$ \\
\hline & Methodology & 51 & 19.3 & $\mathrm{~B}$ & 54.9 & 13.7 & $\mathrm{~B}$ \\
\hline & Relative error & $16.7 \%$ & $-1.5 \%$ & & $19.6 \%$ & $-3.5 \%$ & \\
\hline
\end{tabular}

speed as well as density. The relative error range was $[1.5 \%$, $19.6 \%$ ] for the average speed, while the relative error range was $[-3.5 \%, 13.4 \%]$ for the density. The main cause of the existing relative error was the random VISSIM simulation results which led to some deviations from the average speed and density in the estimated models.

\section{Sensitivity Analysis}

8.1. Impact of Trucks Proportion on the Value of Ellipse Element (a), Density, and Average Speed. To study the influence of different ratios of trucks on geometric design and traffic operation performance for mega elliptical roundabout, the 
TABLE 6: Results of methodology, simulations, and relative error when the traffic volume for the minor highway equals 1000 veh/h.

\begin{tabular}{|c|c|c|c|c|c|c|c|}
\hline \multirow{2}{*}{$\begin{array}{l}\text { Traffic volume for } \\
\text { the major highway }\end{array}$} & & \multicolumn{3}{|c|}{ Part 1 or part 3} & \multicolumn{3}{|c|}{ Part 2 or part 4} \\
\hline & & Average speed (mi/h) & Density (pc/mi/ln) & LOS & Average speed $(\mathrm{mi} / \mathrm{h})$ & Density $(\mathrm{pc} / \mathrm{mi} / \mathrm{ln})$ & LOS \\
\hline \multirow{3}{*}{1000} & VISSIM & 52 & 9.7 & $\mathrm{~A}$ & 49.6 & 10.2 & $\mathrm{~A}$ \\
\hline & Methodology & 52.8 & 11 & A & 52.8 & 11 & A \\
\hline & Relative error & $1.5 \%$ & $13.4 \%$ & & $6.4 \%$ & $7.8 \%$ & \\
\hline \multirow{3}{*}{1500} & VISSIM & 49.8 & 13.2 & B & 44.9 & 13.57 & $\mathrm{~B}$ \\
\hline & Methodology & 51.4 & 14.6 & B & 52.3 & 13.3 & $\mathrm{~B}$ \\
\hline & Relative error & $3.2 \%$ & $10.6 \%$ & & $16.4 \%$ & $-1.9 \%$ & \\
\hline \multirow{3}{*}{2000} & VISSIM & 46.6 & 16.75 & B & 44.3 & 16.2 & $\mathrm{~B}$ \\
\hline & Methodology & 50 & 18.5 & B & 51.8 & 15.7 & $\mathrm{~B}$ \\
\hline & Relative error & $7.3 \%$ & $10.4 \%$ & & $16.9 \%$ & $-3 \%$ & \\
\hline
\end{tabular}

proposed methodology was used to predict the value of an ellipse element $(a)$, density, and average speed at different ratios of trucks. The used scenarios are the same scenarios described in Section 7.1, but with different values of truck ratios which are $2,5,10,15$, and $20 \%$.

The relationships between major highway traffic volume and the value of an ellipse element $(a)$, density, and average speed for vehicles on the weaving sections for mega elliptical roundabout at different ratios of trucks when minor highway traffic volume equals $500 \mathrm{veh} / \mathrm{h}$ and $1000 \mathrm{veh} / \mathrm{h}$ are presented in Figures 6 and 7, respectively. The figures show that the average speed for vehicles decreases with the increase in truck ratios, but the differences are not significant. The decrease in average speed may be because of traffic interaction that occurs due to increasing the truck proportion, while the fact that the differences are not significant may be because mega elliptical roundabout is not conventional intersection. It gives priority to the vehicles entering from the major highway. Therefore, the movement on the weaving sections of mega elliptical roundabout intersection is like the movement on the twosided weaving sections of any highway.

Moreover, the density increases with the increase in truck ratios, but the differences are not significant. This is most likely because the average speed decreases with the increase in truck ratios, thereby increasing the density, as described in equation (16).

In addition, the value of an ellipse element $(a)$ decreases with the increase in truck ratios, but the differences are not significant. This is most likely because the average speed decreases with the increase in truck ratios that can lead to decreasing the value of radius of basic ellipse roadway, as described in equation (13), thereby decreasing the ellipse element (a), as described in equations (14) and (15).

Based on the above analysis, the influence of the different ratios of trucks on geometric design and traffic operation performance for mega elliptical roundabout is not significant.

\subsection{Impact of Major Highway Speed on the Value of Ellipse} Element (a), Density, and Average Speed. To study the influence of different values of a major highway speed on geometric design and traffic operation performance for mega elliptical roundabout, the proposed methodology was used to predict the value of an ellipse element (a), density, and average speed at different values of a major highway speed. The used scenarios are the same scenarios described in Section 7.1, but with different values of a major highway speed which were $30,40,45,50$, and $62 \mathrm{mi} / \mathrm{h}$.

The relationships between major highway traffic volume and the value of an ellipse element $(a)$, density, and average speed for vehicles on the weaving sections for mega elliptical roundabout at different values of a major highway speed when minor highway traffic volume is equal to $500 \mathrm{veh} / \mathrm{h}$ and $1000 \mathrm{veh} / \mathrm{h}$ are presented in Figures 8 and 9, respectively. The figures show that the average speed for vehicles increases with the increase in major highway speed, but the density decreases. This is probably because mega elliptical roundabout gives priority to the vehicles entering from the major highway. Therefore, the movement on the weaving sections of mega elliptical roundabout is like the movement on the two-sided weaving sections of any highway.

Also, the value of an ellipse element (a) increases with the increase in major highway speed because the average speed for vehicles increases, which can lead to increasing the value of radius of basic ellipse roadway, thereby increasing the ellipse element (a), as described in equations (13)-(15). Moreover, the value of an ellipse element $(a)$ has doubled when the major highway speed increased from $30 \mathrm{mi} / \mathrm{h}$ to $40 \mathrm{mi} / \mathrm{h}, 40 \mathrm{mi} / \mathrm{h}$ to $50 \mathrm{mi} / \mathrm{h}$, and $50 \mathrm{mi} / \mathrm{hr}$ to $62 \mathrm{mi} / \mathrm{h}$. This is probably because mega elliptical roundabout island has an ellipse element (b) for providing a suitable radius for basic ellipse roadway in order to be appropriate for heavy vehicles that make a U-turn on basic ellipse roadway. This radius is calculated based on the average speed for vehicles on weaving sections from equation (13).

Furthermore, the average speed on part 2 or part 4 is greater than the average speed on part 1 or part 3 for mega elliptical roundabout in all scenarios. This is probably because total weaving volume on part 2 or part 4 is lower than total weaving volume on part 1 or part 3 , as shown in Figures 3 and 4, thereby increasing the average speed. For the same reason, the value of an ellipse element $(a)$ is always calculated according to the average speed on part 2 or part 4 from equations (14) and (15)

By analyzing Figure 8, it is possible to confirm the following.

In the case of the value of major highway speed equal to $30 \mathrm{mi} / \mathrm{hr}$, minor highway volume $=500 \mathrm{veh} / \mathrm{h}$, ellipse element $(a)=410 \mathrm{ft}$, and major highway volume $\leq 1500 \mathrm{veh} / \mathrm{h}$, density is lower than $32 \mathrm{pc} / \mathrm{mi} / \mathrm{ln}$ (level of service A-B-C). 


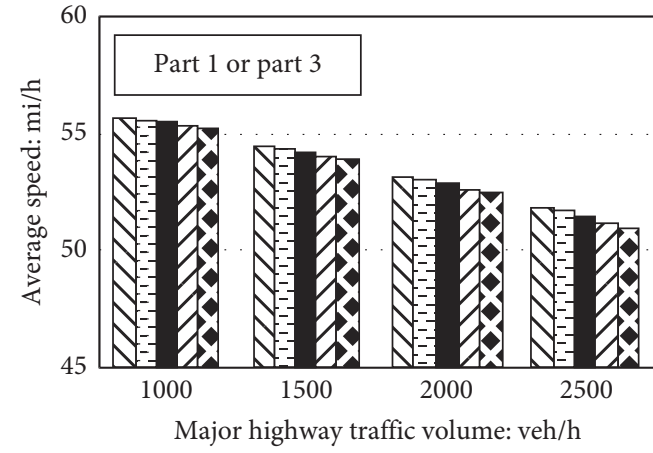

$\mathbb{Q}$ The proportion of trucks and buses $=2 \%$

울 The proportion of trucks and buses $=5 \%$

The proportion of trucks and buses $=10 \%$

$\square$ The proportion of trucks and buses $=15 \%$

The proportion of trucks and buses $=20 \%$

(a)

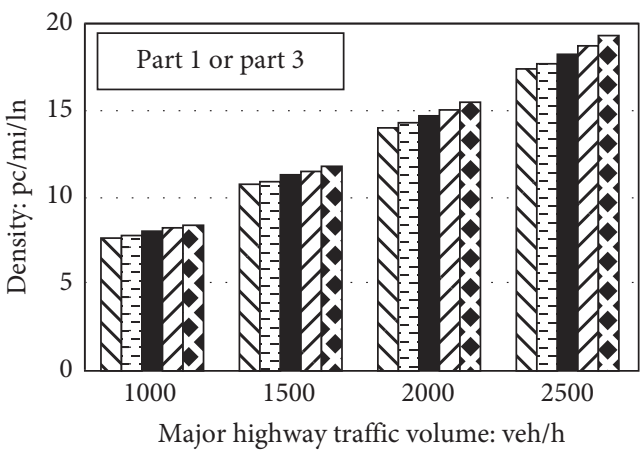

$\mathbb{T}$ The proportion of trucks and buses $=2 \%$

图 The proportion of trucks and buses $=5 \%$

The proportion of trucks and buses $=10 \%$

$\square$ The proportion of trucks and buses $=15 \%$

The proportion of trucks and buses $=20 \%$

(c)

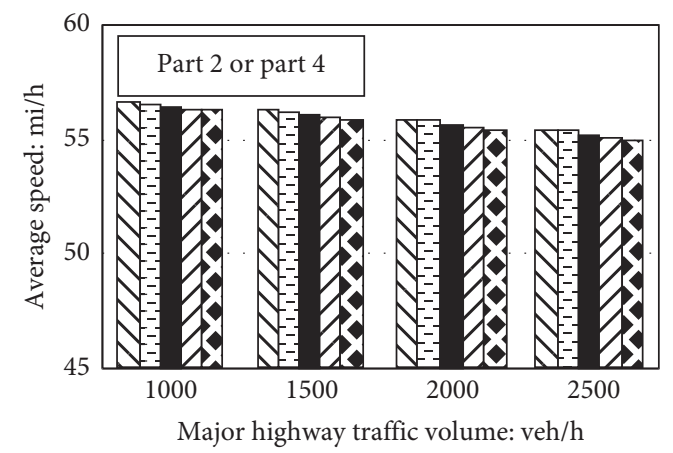

$\mathbb{\mathbb { N }}$ The proportion of trucks and buses $=2 \%$

圈 The proportion of trucks and buses $=5 \%$

The proportion of trucks and buses $=10 \%$

$\square$ The proportion of trucks and buses $=15 \%$

The proportion of trucks and buses $=20 \%$

(b)

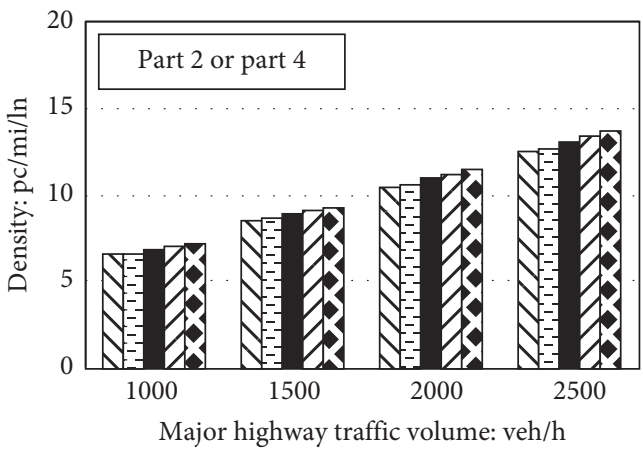

$\mathbb{N}$ The proportion of trucks and buses $=2 \%$

图 The proportion of trucks and buses $=5 \%$

- The proportion of trucks and buses $=10 \%$

$\square$ The proportion of trucks and buses $=15 \%$

The proportion of trucks and buses $=20 \%$

(d)

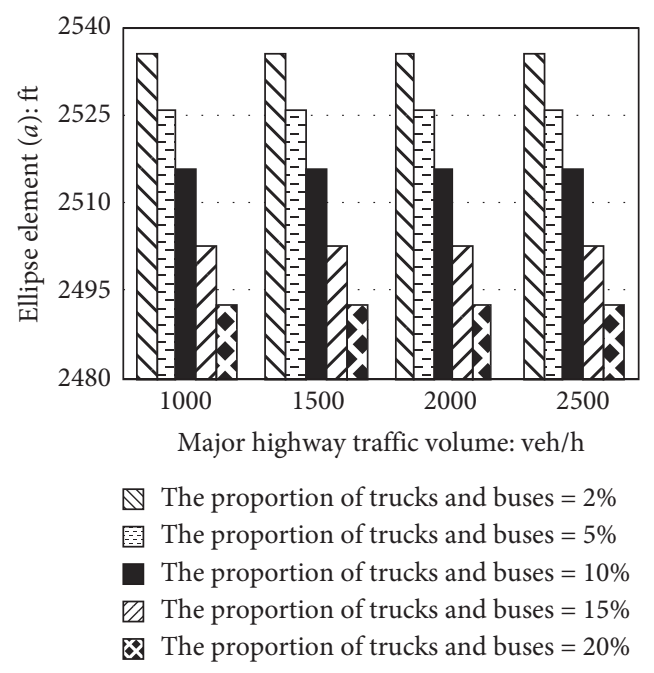

(e)

FIGURE 6: Relationships between major highway traffic volume and the value of an ellipse element (a), density, and average speed at different ratios of trucks when the minor highway traffic volume $=500 \mathrm{veh} / \mathrm{h}$. (a) Average speed for part 1 or part 3 , (b) average speed for part 2 or part 4, (c) density for part 1 or part 3, (d) density for part 2 or part 4, (e) ellipse element (a) for mega roundabout. 


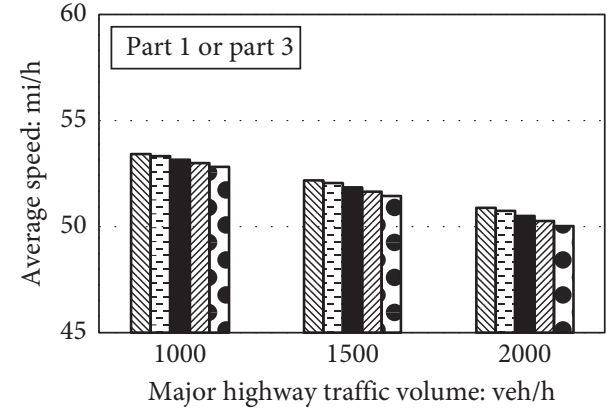

$\mathbb{N}$ The proportion of trucks and buses $=2 \%$

-7 The proportion of trucks and buses $=5 \%$

- The proportion of trucks and buses $=10 \%$

$\square$ The proportion of trucks and buses $=15 \%$

D The proportion of trucks and buses $=20 \%$

(a)

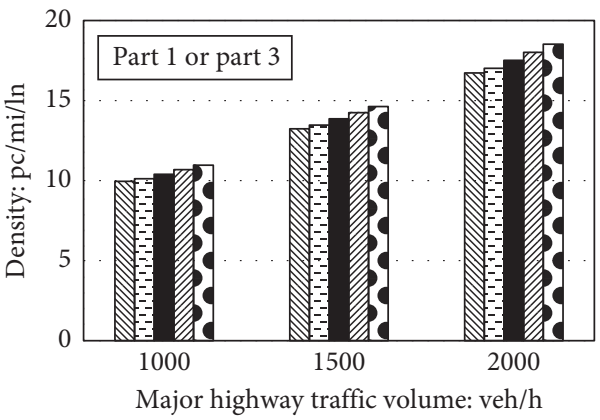

$\mathbb{N}$ The proportion of trucks and buses $=2 \%$

- - The proportion of trucks and buses $=5 \%$

- The proportion of trucks and buses $=10 \%$

$\square$ The proportion of trucks and buses $=15 \%$

D The proportion of trucks and buses $=20 \%$

(c)

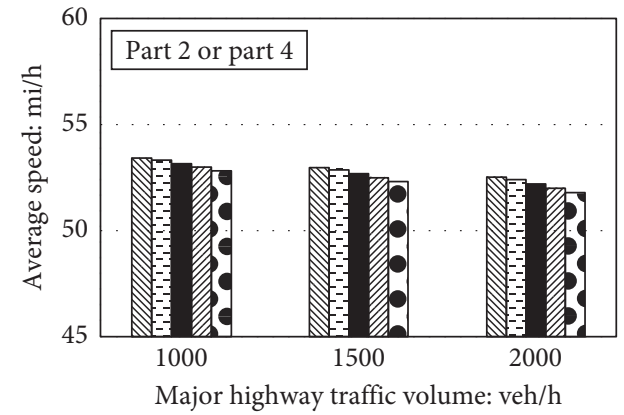

$\mathbb{N}$ The proportion of trucks and buses $=2 \%$

- - The proportion of trucks and buses $=5 \%$

- The proportion of trucks and buses $=10 \%$

$\square$ The proportion of trucks and buses $=15 \%$

D The proportion of trucks and buses $=20 \%$

(b)

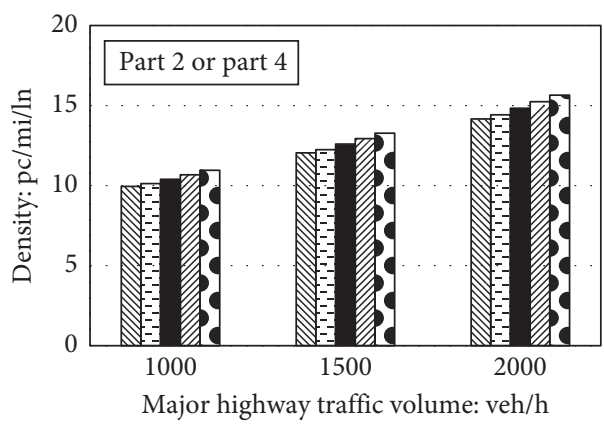

$\mathbb{N}$ The proportion of trucks and buses $=2 \%$

- - The proportion of trucks and buses $=5 \%$

- The proportion of trucks and buses $=10 \%$

$\square$ The proportion of trucks and buses $=15 \%$

D The proportion of trucks and buses $=20 \%$

(d)

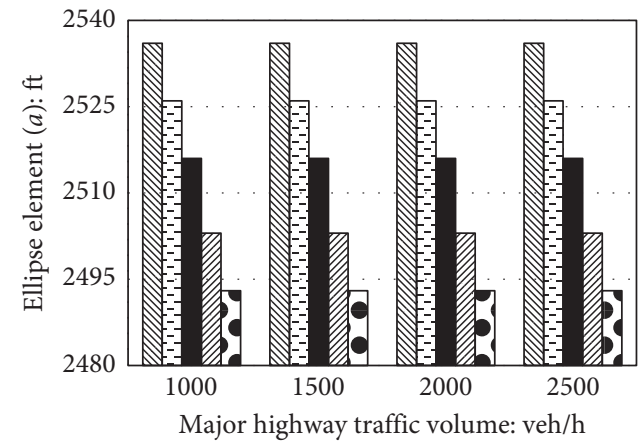

$\mathbb{N}$ The proportion of trucks and buses $=2 \%$

- - The proportion of trucks and buses $=5 \%$

- The proportion of trucks and buses $=10 \%$

$\square$ The proportion of trucks and buses $=15 \%$

D The proportion of trucks and buses $=20 \%$

(e)

FiguRE 7: Relationships between major highway traffic volume and the value of an ellipse element ( $a$ ), density, and average speed at different ratios of trucks when the minor highway traffic volume $=1000 \mathrm{veh} / \mathrm{h}$. (a) Average speed for part 1 or part 3, (b) average speed for part 2 or part 4, (c) density for part 1 or part 3, (d) density for part 2 or part 4, (e) ellipse element (a) for mega roundabout. 


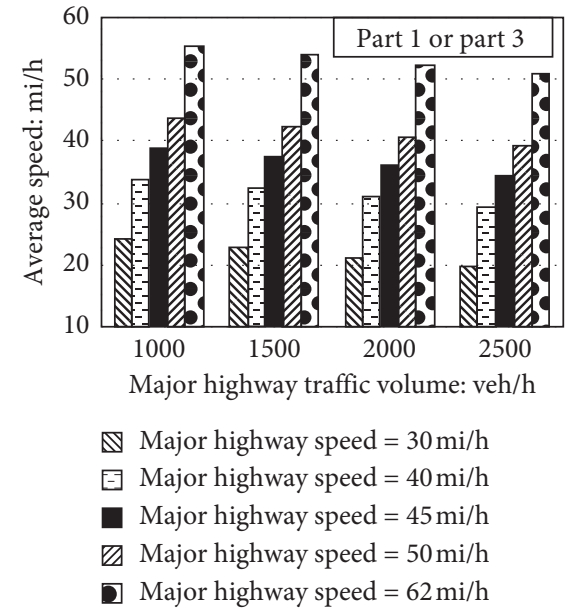

(a)

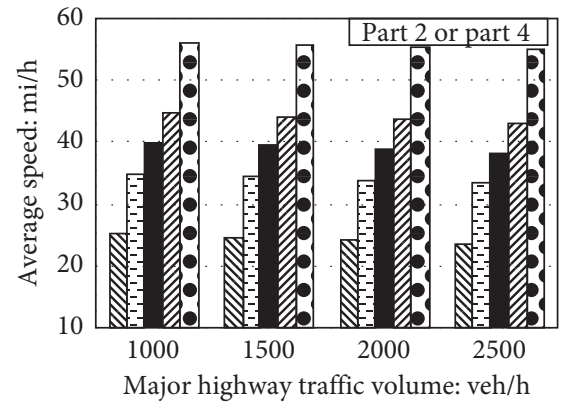

$\mathbb{B}$ Major highway speed $=30 \mathrm{mi} / \mathrm{h}$
—- Major highway speed $=40 \mathrm{mi} / \mathrm{h}$
$\square$ Major highway speed $=45 \mathrm{mi} / \mathrm{h}$
$\mathbb{Z}$ Major highway speed $=50 \mathrm{mi} / \mathrm{h}$
$\square$ Major highway speed $=62 \mathrm{mi} / \mathrm{h}$

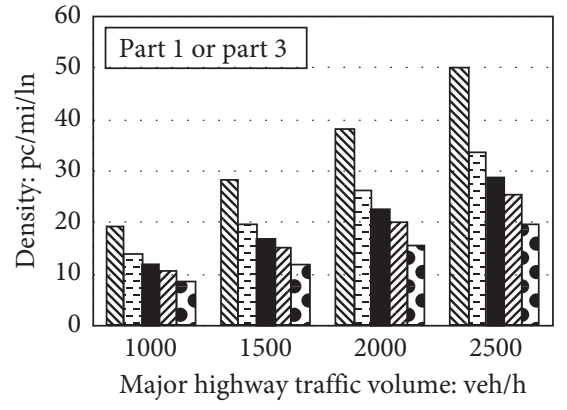

$\mathbb{N}$ Major highway speed $=30 \mathrm{mi} / \mathrm{h}$

- - Major highway speed $=40 \mathrm{mi} / \mathrm{h}$

Major highway speed $=45 \mathrm{mi} / \mathrm{h}$

$\square$ Major highway speed $=50 \mathrm{mi} / \mathrm{h}$

D Major highway speed $=62 \mathrm{mi} / \mathrm{h}$

(b)

(c)

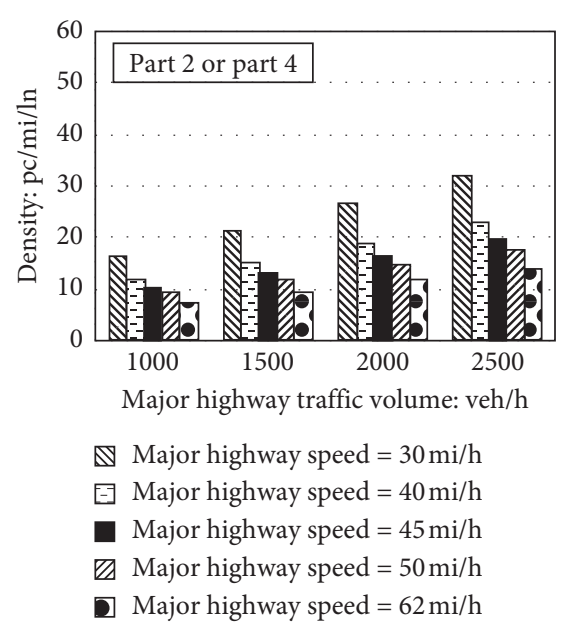

(d)

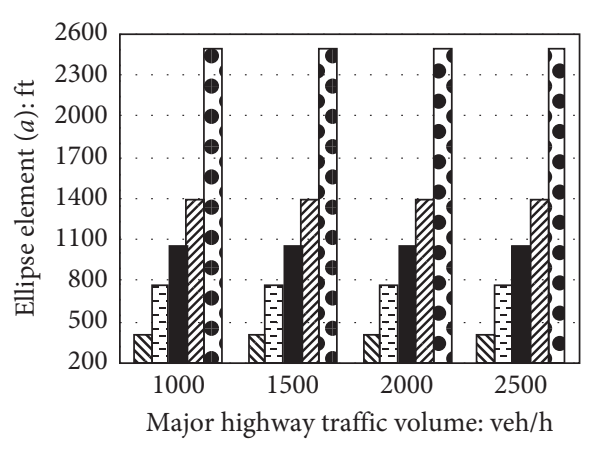

$\mathbb{N}$ Major highway speed $=30 \mathrm{mi} / \mathrm{h}$

-- Major highway speed $=40 \mathrm{mi} / \mathrm{h}$

Major highway speed $=45 \mathrm{mi} / \mathrm{h}$

Z Major highway speed $=50 \mathrm{mi} / \mathrm{h}$

D Major highway speed $=62 \mathrm{mi} / \mathrm{h}$

(e)

FIGURE 8: Relationships between major highway traffic volume and the value of an ellipse element (a), density, and average speed at different values of a major highway speed when minor highway traffic volume $=500 \mathrm{veh} / \mathrm{h}$. (a) Average speed for part 1 or part 3 , (b) average speed for part 2 or part 4 , (c) density for part 1 or part 3, (d) density for part 2 or part 4, (e) ellipse element (a) for mega roundabout.

Also, in the case of the value of major highway speed equal to $40 \mathrm{mi} / \mathrm{hr}$, minor highway volume $=500 \mathrm{veh} / \mathrm{h}$, ellipse element $(a)=771 \mathrm{ft}$, and major highway volume $\leq 2000 \mathrm{veh} / \mathrm{h}$, density is lower than $32 \mathrm{pc} / \mathrm{mi} / \mathrm{ln}$ (level of service A-B-C).

By analyzing Figure 9, it is possible to confirm the following.

In the case of the value of major highway speed equal to $30 \mathrm{mi} / \mathrm{hr}$, minor highway volume $=1000 \mathrm{veh} / \mathrm{h}$, ellipse element $(a)=410 \mathrm{ft}$, and major highway volume $\leq 1000 \mathrm{veh} / \mathrm{h}$, density is lower than $32 \mathrm{pc} / \mathrm{mi} / \mathrm{ln}$ (level of service A-B-C). Also, in the case of the value of major highway speed equal to $40 \mathrm{mi} / \mathrm{hr}$, minor highway volume $=1000 \mathrm{veh} / \mathrm{h}$, ellipse element $(a)=771 \mathrm{ft}$, and major highway volume $\leq 1500 \mathrm{veh} / \mathrm{h}$, density is lower than $32 \mathrm{pc} / \mathrm{mi} / \mathrm{ln}$ (level of service A-B-C).

Based on the above analysis, in highways that have a speed equal to $30 \mathrm{mi} / \mathrm{hr}$, the suitable design of mega elliptical roundabout is ellipse element $(a)=410 \mathrm{ft}$ and ellipse element $(b)=308 \mathrm{ft}$. This is suitable in the following cases: the values of a major highway volume $\leq 1500 \mathrm{veh} / \mathrm{h}$ and minor highway volume $\leq 500 \mathrm{veh} / \mathrm{h}$; or the values of a major highway volume $\leq 1000 \mathrm{veh} / \mathrm{h}$ and minor highway volume $\leq 1000 \mathrm{veh} / \mathrm{h}$. Also, in highways that have a speed equal to $40 \mathrm{mi} / \mathrm{hr}$, the suitable design of mega elliptical roundabout is ellipse element $(a)=771 \mathrm{ft}$ and ellipse element $(b)=578 \mathrm{ft}$. This is suitable the following cases: the values of a major highway volume $\leq 2000 \mathrm{veh} / \mathrm{h}$ and minor highway volume $=500 \mathrm{veh} /$ $\mathrm{h}$; or the values of a major highway volume $\leq 1500 \mathrm{veh} / \mathrm{h}$ and minor highway volume $=1000 \mathrm{veh} / \mathrm{h}$. Moreover, in highways that have a speed equal to 45,50 and $62 \mathrm{mi} / \mathrm{hr}$, the suitable design of mega elliptical roundabout is ellipse element $(b)=0.75$ ellipse element $(a)$, and ellipse element $(a)=1053,1398$, and $2493 \mathrm{ft}$, respectively. This is suitable in the following cases: the values of a major highway volume $\leq 2500 \mathrm{veh} / \mathrm{h}$ and minor highway volume $\leq 500 \mathrm{veh} / \mathrm{h}$; or the values of a major highway volume $\leq 2000 \mathrm{veh} / \mathrm{h}$ and minor highway volume $\leq 1000 \mathrm{veh} / \mathrm{h}$. 


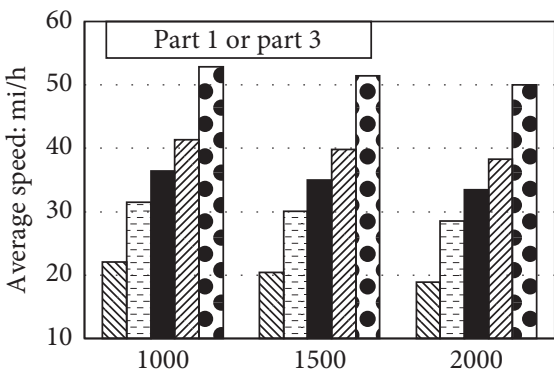

Major highway traffic volume: veh/h

$\mathbb{N}$ Major highway speed $=30 \mathrm{mi} / \mathrm{h}$

E- Major highway speed $=40 \mathrm{mi} / \mathrm{h}$

Major highway speed $=45 \mathrm{mi} / \mathrm{h}$

$\square$ Major highway speed $=50 \mathrm{mi} / \mathrm{h}$

Dajor highway speed $=62 \mathrm{mi} / \mathrm{h}$

(a)

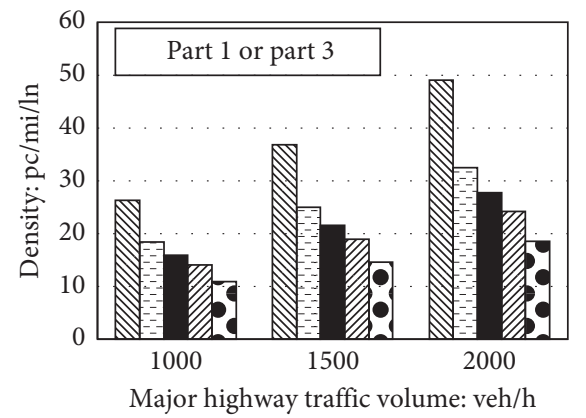

$\mathbb{Q}$ Major highway speed $=30 \mathrm{mi} / \mathrm{h}$

- Major highway speed $=40 \mathrm{mi} / \mathrm{h}$

Major highway speed $=45 \mathrm{mi} / \mathrm{h}$

Major highway speed $=50 \mathrm{mi} / \mathrm{h}$

Major highway speed $=62 \mathrm{mi} / \mathrm{h}$

(c)

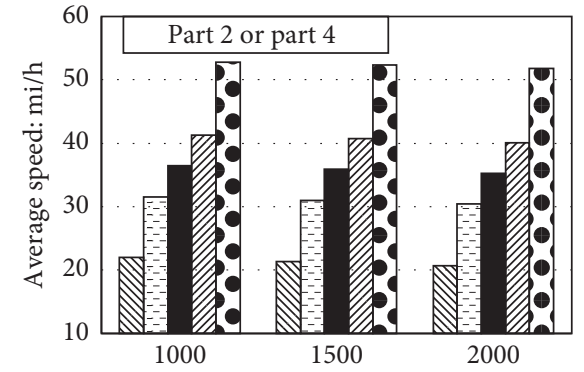

Major highway traffic volume: veh/h

$\mathbb{N}$ Major highway speed $=30 \mathrm{mi} / \mathrm{h}$

- Major highway speed $=40 \mathrm{mi} / \mathrm{h}$

Major highway speed $=45 \mathrm{mi} / \mathrm{h}$

$\square$ Major highway speed $=50 \mathrm{mi} / \mathrm{h}$

D Major highway speed $=62 \mathrm{mi} / \mathrm{h}$

(b)

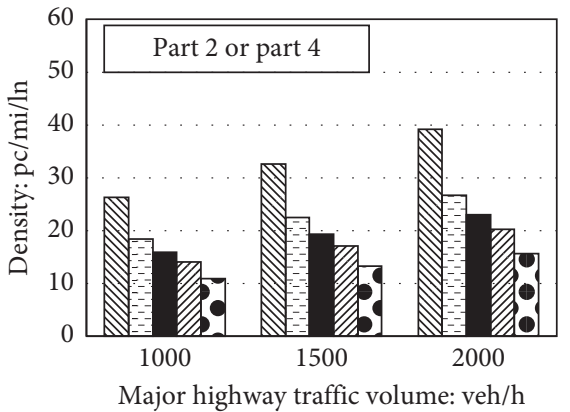

$\mathbb{Q}$ Major highway speed $=30 \mathrm{mi} / \mathrm{h}$

G Major highway speed $=40 \mathrm{mi} / \mathrm{h}$

Major highway speed $=45 \mathrm{mi} / \mathrm{h}$

Major highway speed $=50 \mathrm{mi} / \mathrm{h}$

D Major highway speed $=62 \mathrm{mi} / \mathrm{h}$

(d)

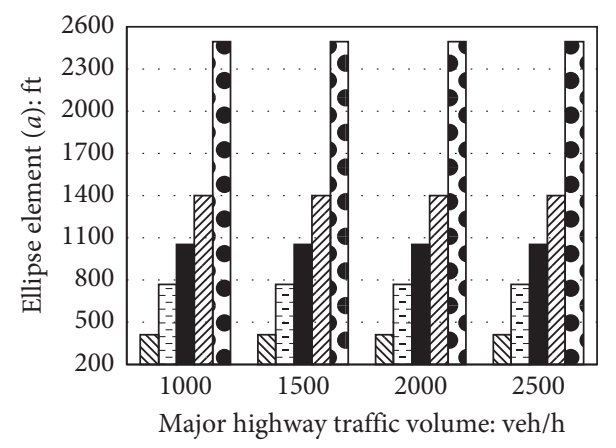

$\mathbb{N}$ Major highway speed $=30 \mathrm{mi} / \mathrm{h}$

- Major highway speed $=40 \mathrm{mi} / \mathrm{h}$

- Major highway speed $=45 \mathrm{mi} / \mathrm{h}$

$\mathbb{Z}$ Major highway speed $=50 \mathrm{mi} / \mathrm{h}$

Dajor highway speed $=62 \mathrm{mi} / \mathrm{h}$

(e)

FigURE 9: Relationships between major highway traffic volume and the value of an ellipse element ( $a$ ), density, and average speed at different values of a major highway speed when minor highway traffic volume $=1000 \mathrm{veh} / \mathrm{h}$. (a) Average speed for part 1 or part 3, (b) average speed for part 2 or part 4, (c) density for part 1 or part 3, (d) density for part 2 or part 4, (e) ellipse element (a) for mega roundabout. 


\section{Conclusions}

In this paper, the performance of traffic operations was analyzed for mega elliptical roundabout intersection. Moreover, this paper proposed a methodology for estimating the capacity and level of service for mega elliptical roundabout intersections by gap acceptance theory. Furthermore, explicit VISSIM simulations were performed after calibrating them with field data from real two-sided weaving sections in Harbin to verify the accuracy of the proposed methodology. In addition, regression analysis was implemented by SPSS software to obtain the relationships of ellipse elements with the radius of basic ellipse roadway, the length of basic ellipse roadway, and the length of weaving section. Regression models were developed using the data that were compiled by the AutoCAD software for several geometric design scenarios for mega elliptical roundabout intersection. Also, the influence of different values of truck ratios and also different values of a major highway speed on geometric design and traffic operation performance for mega elliptical roundabout was studied. Based on the regression analysis, methodology validation, and sensitivity analysis, the following can be concluded:

(1) In mega elliptical roundabout intersection, the weaving sections are the key to the efficiency of the intersection as a whole

(2) The models built up in this study are adequate to predict the dependent variables

(3) Estimation methodology of the average speed and the density on the weaving sections of mega elliptical roundabout was confirmed to have a reasonable accuracy

(4) The influence of the different ratios of trucks on geometric design and traffic operation performance for mega elliptical roundabout is not significant, while the influence of the different ratios of a major highway speed is significant

In conclusion, it is clear that this study analyzed the performance of traffic operations and suggested a method for designing mega elliptical roundabout intersections to assist practitioners in determining the appropriate geometric design. Based on the previous studies, the traffic operation and safety are the main measures for assessing the intersections [72-76]. Therefore, further research will be needed to assess the safety performance of mega elliptical roundabout. We plan to use a surrogate safety assessment model developed by FHWA to compare safety aspects of the proposed intersection with those of other alternative intersections.

\section{Data Availability}

The basic data used to support the findings of this study are available from the corresponding author upon request.

\section{Conflicts of Interest}

The authors declare that there are no conflicts of interest.

\section{Authors' Contributions}

Ahmed I. Z. Mohamed and Yusheng Ci collected the data and analyzed and interpreted the results. Ahmed I. Z. Mohamed and Yiqiu Tan prepared the manuscript draft. All authors contributed to study conception and design, reviewed the results, and approved the final version of the manuscript.

\section{Acknowledgments}

The first author thanks the Ministry of Education of China for the Ph.D. scholarship they provided under CSC grant (no. 2017GBJ001910). Also, this project was financially supported by grants from the National Key R\&D Program of China (no. 2017YFC0803907) and the MOE Project of Humanities and Social Sciences, China (no. 16YJCZH114).

\section{References}

[1] FHWA (Federal Highway Administration), Diverging Diamond Interchange Informational Guide, Federal Highway Administration Office of Safety, Washington, DC, USA, 2014.

[2] FHWA, Displaced Left Turn Intersection Informational Guide, Federal Highway Administration Office of Safety, Washington, DC, USA, 2014.

[3] FHWA, Median U-Turn Intersection Informational Guide, Federal Highway Administration Office of Safety, Washington, DC, USA, 2014.

[4] FHWA, Restricted Crossing U-Turn Intersectional Information Guide, Federal Highway Administration Office of Safety, Washington, DC, USA, 2014.

[5] A. I. Z. Mohamed, Y. Ci, and Y. Tan, "Mega elliptical roundabouts versus grade-separation interchange," Proceedings of the Institution of Civil Engineers-Transport, pp. 1-21, 2019.

[6] V. Tabernero and T. Sayed, "Upstream signalized crossover intersection: an unconventional intersection scheme," Journal of Transportation Engineering, vol. 132, no. 11, pp. 907-911, 2006.

[7] E. K. Shin, J. H. Lee, J. H. Kim, J. S. Kim, and Y. W. Jeong, "Two-level signalized intersection," Transportation Research Record: Journal of the Transportation Research Board, vol. 2060, no. 1, pp. 53-64, 2008.

[8] J. Reid, F. Ngai, and D. VanMeter, "Introduction of the dualsystem urban interchange design," Transportation Research Record: Journal of the Transportation Research Board, vol. 2065, no. 1, pp. 27-35, 2008.

[9] M. E. Esawey and T. Sayed, "Unconventional USC intersection corridors: evaluation of potential implementation in Doha, Qatar," Journal of Advanced Transportation, vol. 45, no. 1, pp. 38-53, 2011.

[10] M. A. Sultana, A. Tarko, and M. Romero, "Evaluating the operational footprint of alternative diamond interchanges," Journal of Transportation Engineering, Part A: Systems, vol. 144, no. 9, pp. 1-11, 2018.

[11] L. F. Sutherland, D. J. Cook, and K. K. Dixon, "Operational effects of the displaced partial cloverleaf interchange," Transportation Research Record: Journal of the Transportation Research Board, vol. 2672, no. 17, pp. 108-119, 2018.

[12] A. M. Molana and J. E. Hummer, "Travel time evaluation of synchronized and milwaukee B as new interchange designs," 
Journal of Transportation Engineering, Part A: Systems, vol. 144, no. 2, pp. 1-8, 2018.

[13] N. Mitrovic, I. Dakic, and A. Stevanovic, "Using analytical models to calibrate a dual-roundabout intersection in microsimulation," Put I Saobraćaj, vol. 64, no. 2, pp. 13-19, 2018.

[14] A. M. Molan, J. E. Hummer, and K. Ksaibati, "Introducing the super DDI as a promising alternative service interchange," Transportation Research Record: Journal of the Transportation Research Board, vol. 2673, no. 3, pp. 586-597, 2019.

[15] J. Shahi and A.-A. Choupani, "Modelling the operational effects of unconventional U-turns at a highway intersection," Transportmetrica, vol. 5, no. 3, pp. 173-191, 2009.

[16] P. Liu, J. Wan, W. Wang, and Z. Li, "Evaluating the impacts of unconventional outside left-turn lane design on traffic operations at signalized intersections," Transportation Research Record: Journal of the Transportation Research Board, vol. 2257, no. 1, pp. 62-70, 2011.

[17] C. Yeom, B. J. Schroeder, C. Cunningham, C. Vaughan, N. M. Rouphail, and J. E. Hummer, "Lane utilization at twolane arterial approaches to double crossover diamond interchanges," Transportation Research Record: Journal of the Transportation Research Board, vol. 2461, no. 1, pp. 103-112, 2014.

[18] C. Yeom, J. E. Hummer, B. Schroeder, C. M. Cunningham, C. L. Vaughan, and N. M. Rouphail, "Empirical before-after comparison of the operational performance of diverging and conventional diamond interchanges," Journal of Transportation of the Institute of Transportation Engineers (ITE), vol. 7, no. 1, pp. 35-55, 2015.

[19] N. Wu, "Determination of capacity at all-way stop-controlled intersections," Transportation Research Record: Journal of the Transportation Research Board, vol. 1710, no. 1, pp. 205-214, 2000.

[20] M. Kyte and G. List, "A capacity model for all-way stopcontrolled intersections based on stream interactions," Transportation Research Part A: Policy and Practice, vol. 33, no. 3-4, pp. 313-335, 1999.

[21] W. Brilon and N. Wu, "Capacity at unsignalized intersections derived by conflict technique," Transportation Research Record: Journal of the Transportation Research Board, vol. 1776, no. 1, pp. 82-90, 2001.

[22] W. Brilon and T. Miltner, "Capacity at intersections without traffic signals," Transportation Research Record: Journal of the Transportation Research Board, vol. 1920, no. 1, pp. 32-40, 2005.

[23] H. Li, W. Deng, Z. Tian, and P. Hu, "Capacities of unsignalized intersections under mixed vehicular and nonmotorized traffic conditions," Transportation Research Record: Journal of the Transportation Research Board, vol. 2130, no. 1, pp. 129137, 2009.

[24] A.-Z. Li, X.-H. Song, X.-S. Song, and B.-H. Wu, "Capacity of urban road unsignalized T-intersection," in Proceedings of the 2010 International Conference On Computational Intelligence and Software Engineering, Wuhan, China, December 2010.

[25] H. Li, Z. Tian, and W. Deng, "Capacity of TWSC intersection with multilane approaches," Procedia-Social and Behavioral Sciences, vol. 16, pp. 664-675, 2011.

[26] Y. Pei, F. Chuanyun, and P. Ting, "Theory model for traffic capacity of unsignalized roundabout in urban road," in Proceedings of the Third International Conference on Transportation Engineering (ICTE), Chengdu, China, July 2011.

[27] S. I. Guler and M. Menendez, "Methodology for estimating capacity and vehicle delays at unsignalized multimodal intersections," International Journal of Transportation Science and Technology, vol. 5, no. 4, pp. 257-267, 2016.

[28] W. Ma, Y. Liu, J. Zhao, and N. Wu, "Increasing the capacity of signalized intersections with left-turn waiting areas," Transportation Research Part A: Policy and Practice, vol. 105, pp. 181-196, 2017.

[29] L. Wu, Y. Ci, Y. Wang, and P. Chen, "Fuel consumption at the oversaturated signalized intersection considering queue effects: a case study in Harbin, China," Energy, vol. 192, Article ID 116654, , 2020.

[30] O. Hagring, "Derivation of capacity equation for roundabout entry with mixed circulating and exiting flows," Transportation Research Record: Journal of the Transportation Research Board, vol. 1776, no. 1, pp. 91-99, 2001.

[31] Z. Qu, Y. Duan, X. Song, H. Hu, H. Liu, and K. Guan, "Capacity prediction model based on limited priority gapacceptance theory at multilane roundabouts," Mathematical Problems in Engineering, vol. 2014, Article ID 490280, 11 pages, 2014.

[32] A. N. Arshi, W. K. M. Alhajyaseen, H. Nakamura, and $\mathrm{X}$. Zhang, "A comparative study on the operational performance of four-leg intersections by control type," Transportation Research Part A: Policy and Practice, vol. 118, pp. 52-67, 2018.

[33] L. Mussone, M. Matteucci, M. Bassani, and D. Rizzi, "An innovative method for the analysis of vehicle movements in roundabouts based on image processing," Journal of Advanced Transportation, vol. 47, 2011.

[34] J. Dahi and C. Lee, "Empirical estimation of capacity for roundabouts using adjusted gap-acceptance parameters for trucks," Transportation Research Record: Journal of the Transportation Research Board, vol. 2312, no. 1, pp. 34-45, 2012.

[35] T. Wei and J. L. Grenard, "Calibration and validation of highway capacity manual 2010 capacity model for single-lane roundabouts," Transportation Research Record: Journal of the Transportation Research Board, vol. 2286, no. 1, pp. 105-110, 2012.

[36] C. Lee and M. N. Khan, "Prediction of capacity for roundabouts based on percentages of trucks in entry and circulating flows," Transportation Research Record: Journal of the Transportation Research Board, vol. 2389, no. 1, pp. 30-41, 2013.

[37] A. Ahmad and R. Rastogi, "Regression model for entry capacity of a roundabout under mixed traffic condition-an Indian case study," Transportation Letters, vol. 9, no. 5, pp. 243-257, 2016.

[38] A. K. Patnaik, A. R. Ranjan, and P. K. Bhuyan, "Investigating entry capacity models of roundabouts under heterogeneous traffic conditions," Transportation Research Record: Journal of the Transportation Research Board, vol. 2672, no. 15, pp. 35-43, 2018.

[39] R. Chen and J. Hourdos, "Evaluation of the roundabout capacity model in HCM6 edition and HCM 2010 on a multilane roundabout," Transportation Research Record: Journal of the Transportation Research Board, vol. 2672, no. 15, pp. 23-34, 2018.

[40] E. Chevallier and L. Leclercq, "Microscopic dual-regime model for single-lane roundabouts," Journal of Transportation Engineering, vol. 135, no. 6, pp. 386-394, 2009.

[41] M. Martin-Gasulla, A. Garcia, A. T. Moreno, and C. Llorca, "Capacity and operational improvements of metering roundabouts in Spain," Transportation Research Procedia, vol. 15, pp. 295-307, 2016. 
[42] W. Suh, J. I. Kim, H. Kim, J. Ko, and Y.-J. Lee, "Mathematical analysis for roundabout capacity," Mathematical Problems in Engineering, vol. 2018, Article ID 4310894, 8 pages, 2018.

[43] O. Giuffrè, A. Granà, M. L. Tumminello, and A. Sferlazza, "Capacity-based calculation of passenger car equivalents using traffic simulation at double-lane roundabouts," Simulation Modelling Practice and Theory, vol. 81, pp. 11-30, 2018.

[44] Z. Qu, Y. Duan, H. Hu, and X. Song, "Capacity and delay estimation for roundabouts using conflict theory," The Scientific World Journal, vol. 2014, Article ID 710938, 12 pages, 2014.

[45] J. Bie, H. K. Lo, and S. C. Wong, "Capacity evaluation of multi-lane traffic roundabout," Journal of Advanced Transportation, vol. 44, no. 4, pp. 245-255, 2010.

[46] A.-S. A. Al-Sobky and I. H. Hashim, "A generalized mathematical model to determine the turning movement counts at roundabouts," Alexandria Engineering Journal, vol. 53, no. 3, pp. 669-675, 2014.

[47] A. K. Patnaik, Y. Krishna, S. Rao, and P. K. Bhuyan, "Development of roundabout entry capacity model using INAGA method for heterogeneous traffic flow conditions," Arabian Journal for Science and Engineering, vol. 42, no. 9, pp. 41814199, 2017.

[48] Y. H. Yap, H. M. Gibson, and B. J. Waterson, "An international review of roundabout capacity modelling," Transport Reviews, vol. 33, no. 5, pp. 593-616, 2013.

[49] J. M. Diah, M. Y. A. Rahman, M. A. Adnan, and I. Atan, "Weaving section flow model at the weaving area of Malaysian conventional roundabout," Journal of Transportation Engineering, vol. 136, no. 8, pp. 782-792, 2010.

[50] J. M. Diah, M. Y. A. Rahman, M. A. Adnan, and K. H. Ling, "Modeling the relationship between geometric design and weaving section flow process of conventional roundabouts," Journal of Transportation Engineering, vol. 137, no. 12, pp. 980-986, 2011.

[51] W. Wang and X. Yang, "Research on capacity of roundabouts in beijing," Procedia-Social and Behavioral Sciences, vol. 43, pp. 157-168, 2012.

[52] N. Wu and W. Brilon, "Total capacity of roundabouts analyzed by a conflict technique," Transportation Research Record: Journal of the Transportation Research Board, vol. 2672, no. 15, pp. 9-22, 2018.

[53] HCM (Highway Capacity Manual), Highway Capacity Manual 6th Edition/A Guide for Multimodal Mobility Analysis, Transportation Research Board, Washington, DC, USA, 2016.

[54] H. R. Al-masaeid, "Capacity of U-turn at median openings," Journal of Transportation of the Institute of Transportation Engineers (ITE), vol. 69, no. 6, pp. 28-30, 1999.

[55] J. Lu, S. Dissanayake, H. Zhou, and X. K. Yang, Operational Evaluation of Right Turns Followed by U-Turns as an Alternative to Direct Left Turns, Vol. III, Florida Department of Transportation, Tallahassee, FL, USA, 2001.

[56] J. Lu, P. Liu, J. Fan, and J. Pernia, Operational Evaluation of Right Turns Followed by U-Turns at Signalized Intersections (6 or More Lanes) as an Alternative to Direct Left Turns, Florida Department of Transportation, Tallahassee, FL, USA, 2004.

[57] J. J. Lu and P. Liu, Operational Evaluation of Right Turns Followed by U-Turns (4-Lane Arterials) as an Alternative to Direct Left Turns, Florida Department of Transportation, Tallahassee, FL, USA, 2005.

[58] H. Zhou, J. Lu, X. Yang, S. Dissanayake, and K. M. Williams, "Operational effects of U-turns as alternatives to direct left turns from driveways," Transportation Research Record:
Journal of the Transportation Research Board, vol. 1796, no. 1, pp. 72-79, 2002.

[59] H. Zhou, P. Hsu, J. J. Lu, and J. E. Wright, "Optimal location of U-turn median openings on roadways," Transportation Research Record: Journal of the Transportation Research Board, vol. 1847, no. 1, pp. 36-41, 2003.

[60] P. Liu, J. J. Lu, H. Zhou, and G. Sokolow, "Operational effects of U-turns as alternatives to direct left-turns," Journal of Transportation Engineering, vol. 133, no. 5, pp. 327-334, 2007.

[61] J. Zhao, W. Ma, K. L. Head, and X. Yang, "Optimal intersection operation with median U-turn: lane-based approach," Transportation Research Record: Journal of the Transportation Research Board, vol. 2439, no. 1, pp. 71-82, 2014.

[62] S. Dash, S. S. Mohapatra, and P. P. Dey, "Estimation of critical gap of U-turns at uncontrolled median openings," Transportation Letters, vol. 11, no. 5, pp. 229-240, 2017.

[63] P. Lertworawanich and L. Elefteriadou, "Capacity estimations for type B weaving areas based on gap acceptance," Transportation Research Record: Journal of the Transportation Research Board, vol. 1776, no. 1, pp. 24-34, 2001.

[64] P. Lertworawanich and L. Elefteriadou, "A methodology for estimating capacity at ramp weaves based on gap acceptance and linear optimization," Transportation Research Part B: Methodological, vol. 37, no. 5, pp. 459-483, 2003.

[65] P. Lertworawanich and L. Elefteriadou, "Generalized capacity estimation model for weaving areas," Journal of Transportation Engineering, vol. 133, no. 3, pp. 166-179, 2007.

[66] HCM (Highway Capacity Manual), Highway Capacity Manual, Transportation Research Board, Washington, DC, USA, 2000.

[67] R. P. Roess and E. S. Prassas, "The highway capacity manual: a conceptual and research history volume 1: uninterrupted flow," in Springer Tracts on Transportation and Traffic (STTT), vol. 5Berlin, Germany, Springer, 2014.

[68] H. Rakha and Y. Zhang, "Analytical procedure for estimating capacity of type B weaving sections," in Proceedings of the Presented at 84th Annual Meeting of the Transportation Research Board, Washington, DC, USA, January 2005.

[69] H. Rakha and Y. Zhang, "Systematic analysis of capacity of weaving sections," in Proceedings of the Presented at 84th Annual Meeting of the Transportation Research Board, Washington, DC, USA, 2005.

[70] AASHTO (American Association of State Highway and Transportation Officials), "Green book," in A Policy On Geometric Design Of Highways and Streets, American Association of State Highway and Transportation Officials, Washington, DC, USA, 2011.

[71] P. T. Vo, "Capacity estimation of two-sided type $C$ weaves on freeways," Doctoral dissertation, University of Texas at Arlington, Arlington, TX, USA, 2007.

[72] A. M. Molan and J. E. Hummer, "Safety analysis of the new synchronized and milwaukee B interchanges in comparison to existing designs," Accident Analysis \& Prevention, vol. 109, pp. 29-35, 2017.

[73] F. Chen and S. Chen, "Injury severities of truck drivers in single- and multi-vehicle accidents on rural highways," Accident Analysis \& Prevention, vol. 43, no. 5, pp. 1677-1688, 2011.

[74] F. Chen, S. Chen, and X. Ma, "Analysis of hourly crash likelihood using unbalanced panel data mixed logit model and real-time driving environmental big data," Journal of Safety Research, vol. 65, pp. 153-159, 2018.

[75] F. Chen, M. Song, and X. Ma, "Investigation on the injury severity of drivers in rear-end collisions between cars using a 
random parameters bivariate ordered probit model," International Journal of Environmental Research and Public Health, vol. 16, no. 14, p. 2632, 2019.

[76] A. M. Molana, J. E. Hummerb, and K. Ksaibatia, "Modeling safety performance of the new super DDI design in terms of vehicular traffic and pedestrian," Accident Analysis and Prevention, vol. 127, pp. 198-209, 2019. 